OPEN ACCESS

Edited by: Laura Crane,

University College London, United Kingdom

Reviewed by:

Vikram Jaswal,

University of Virginia, United States

Kayden M. Stockwell,

University of Virginia, United States, in

collaboration with reviewer $V J$ Monique Botha,

University of Stirling, United Kingdom

*Correspondence:

Noah J. Sasson

nsasson@utdallas.edu

Specialty section: This article was submitted to

Cognition,

a section of the journal

Frontiers in Psychology

Received: 04 August 2020 Accepted: 30 October 2020

Published: 25 November 2020

Citation:

Morrison KE, DeBrabander KM

Jones $D R$, Ackerman RA and

Sasson NJ (2020) Social Cognition,

Social Skill, and Social Motivation

Minimally Predict Social Interaction

Outcomes for Autistic and Non-Autistic Adults.

Front. Psychol. 11:591100.

doi: 10.3389/fpsyg.2020.591100

\section{Social Cognition, Social Skill, and Social Motivation Minimally Predict Social Interaction Outcomes for Autistic and Non-Autistic Adults}

\author{
Kerrianne E. Morrison, Kilee M. DeBrabander, Desiree R. Jones, Robert A. Ackerman and \\ Noah J. Sasson*
}

School of Behavioral and Brain Sciences, The University of Texas at Dallas, Richardson, TX, United States

Social cognition, social skill, and social motivation have been extensively researched and characterized as atypical in autistic people, with the assumption that each mechanistically contributes to the broader social interaction difficulties that diagnostically define the condition. Despite this assumption, research has not directly assessed whether or how these three social domains contribute to actual real-world social interaction outcomes for autistic people. The current study administered standardized measures of social cognition, social skill, and social motivation to 67 autistic and 58 non-autistic (NA) adults and assessed whether performance on these measures, both individually and relationally between dyadic partners, predicted outcomes for autistic and NA adults interacting with unfamiliar autistic and NA partners in a 5 minute unstructured "get to know you" conversation. Consistent with previous research, autistic adults scored lower than NA adults on the three social domains and were evaluated less favorably by their conversation partners. However, links between autistic adults' performance on the three social domains and their social interaction outcomes were minimal and, contrary to prediction, only the social abilities of NA adults predicted some interaction outcomes within mixed diagnostic dyads. Collectively, results suggest that reduced performance by autistic adults on standardized measures of social cognition, social skill, and social motivation do not correspond in clear and predictable ways with their real-world social interaction outcomes. They also highlight the need for the development and validation of more ecological assessments of autistic social abilities and the consideration of relational dynamics, not just individual characteristics, when assessing social disability in autism.

Keywords: social interaction, social cognition, social skills, first impressions, double empathy

\section{INTRODUCTION}

Autism Spectrum Disorder (ASD) is clinically defined in part by "persistent deficits in social communication and social interaction" (APA, 2013). Although the focus on communication and interaction necessitates consideration of interpersonal and relational dynamics, the focus on deficits-or reductions in normative characteristics presumed to underlie autistic disability-has historically centered research and treatment at the level of the individual. Indeed, a deep literature has accumulated cataloging how autistic people differ from non-autistic (NA) people in 
their neurology, cognition, and behavior (Pelphrey et al., 2004; Chevallier et al., 2012a; Morrison et al., 2017, 2019b), and a wide variety of intervention programs have been developed using this evidence base to try to normalize individual characteristics with the presumption that doing so may reduce or mitigate autistic disability (for a review, see Pallathra et al., 2019). For autistic adults without intellectual disability, most of these programs are psychosocial in nature and target three primary domains of social ability: social cognition, social skill, and social motivation. Each has been characterized as a core autistic deficit and are assumed to underlie the occupational challenges (Taylor et al., 2015), social isolation (Mazurek, 2014), and reduced quality of life (Billstedt et al., 2005) often experienced by autistic adults.

Social cognition refers to the perception and interpretation of social information (Brothers, 1990) and is often conceptualized as encompassing social perception (i.e., the prioritization and detection of social information), emotion recognition (i.e., accurately identifying the emotional state of others), and theory of mind (i.e., inferring the thoughts and intentions of other people; Baron-Cohen, 1991; Happé, 1994; Mathersul et al., 2013). On average, autistic adults score lower than NA controls on standalone assessments on each subdomain (Morrison et al., 2019b). They score lower on tasks assessing face recognition (e.g., Klin et al., 1999; Joseph and Tanaka, 2003), the identification of emotion from facial expressions, voices, and social scenes (e.g., Golan et al., 2007; Kennedy and Adolphs, 2012; Uljarevic and Hamilton, 2013; Sasson et al., 2016), and the inference of other peoples' intentions and mental states (e.g., Spek et al., 2010; Mathersul et al., 2013). Although these difficulties are presumed to mechanistically relate to the poor social and functional outcomes autistic adults often experience (Sasson et al., 2011), the surprisingly small number of studies that have empirically tested this assumption tend to find only modest relationships (Klin et al., 2002; Lerner and Mikami, 2012; Bishop-Fitzpatrick et al., 2014; Hanley et al., 2014; Deschrijver et al., 2016; Sasson et al., 2020), and no studies to our knowledge have tested whether individual social cognitive performance demonstrates meaningful associations to real-world social interaction for autistic adults. Given that social cognition is often targeted for improvement in psychosocial interventions as a means for enhancing social interaction, the lack of evidence in this regard reflects a significant oversight.

Social skill, meanwhile, is a broad umbrella term referring to the repertoire of behaviors used to navigate social demands and achieve social goals across varying contexts (Mueser and Bellack, 1998). A diverse set of skills have been conceptualized to comprise social skill, ranging from the use of interpersonal eye gaze to more complex competencies like negotiation ability (Mueser and Bellack, 1998; Nangle et al., 2010). Social skills reliably differ in autism (Constantino et al., 2000; Hus and Lord, 2014), with autistic adults often exhibiting non-normative social behaviors within social interactions relative to NA controls (Bishop, 1998; Patterson et al., 2001; Verhoeven et al., 2013). These differences can include atypical use of gaze, less observable conversational involvement, reduced verbal fluency, atypical affect, and asking fewer questions of their interaction partner (Ratto et al., 2011; Morrison et al., 2017). Training programs targeting social skills to improve social functioning among autistic adolescents and adults have yielded some limited benefits (Wykes et al., 2008; Bishop-Fitzpatrick et al., 2014), but they tend to lack generalizability to real-world outcomes (Palmen et al., 2010; Gates et al., 2017; Bottema-Beutel et al., 2018). This may stem in part from an overreliance on examining autistic social skill as an isolated, individual characteristic rather than assessing how it manifests within the context of actual interaction in which relational dynamics and not just individual behavior dictate outcomes (Milton, 2012; Bolis et al., 2018). It also suggests that a single, normative standard for social skill may not conform equally to the communication preferences and expectations of all groups or individuals. Indeed, this criticism is central to the Double Empathy theory of autism (Milton, 2012), which argues that social barriers between autistic and NA people are not solely driven by autistic misunderstanding of NA communication and behavior (as commonly described within autism research) but also the reverse: NA people often exhibit difficulty inferring the mental states and interpreting the social cues of autistic people (Edey et al., 2016; Alkhaldi et al., 2019). From this perspective, social skill is relative, contextual, and necessitates a focus on relational dynamics rather than individual ability.

Finally, social motivation refers to the seeking and liking of social information and relationships (Berridge et al., 2009; Chevallier et al., 2012a). Young children on the autism spectrum often demonstrate reduced attention and divergent reward responses for social information from early in life (Baranek, 1999; Pierce et al., 2011; Chevallier et al., 2012a; Moriuchi et al., 2017), which is theorized to produce cascading effects on developing social neural networks that manifest over time in divergent social behaviors and social cognitive abilities relative to same age peers (Dawson et al., 2005; Chevallier et al., 2012a). In older autistic children and adolescents, some work suggests that diminished social motivation may result in fewer social exchanges and less effort toward maintaining relationships (e.g., Chevallier et al., 2012b). However, many other studies have found that social motivation is highly variable among autistic adolescents and adults (Garman et al., 2016), most of whom express similar desires for friendships and relationships as their NA peers (Bauminger and Kasari, 2000; Whitehouse et al., 2009; Lasgaard et al., 2010; Mazurek, 2014). Higher social motivation among autistic individuals may relate to having better quality friendships, engaging in more social interactions, and displaying higher rates of prosocial behavior in interactions with others (Chevallier et al., 2012b; Dean et al., 2014; Sedgewick et al., 2016). At the same time, lower or different social interest is not inherently negative (Dawson and Cowen, 2019; Fletcher-Watson and Crompton, 2019), and pressure to conform to normative expectations can be detrimental to autistic well-being (Cage and Troxell-Whitman, 2019). For instance, many autistic adolescents and adults without intellectual disability report engaging in effortful and often exhausting "camouflaging" behaviors in order to appear more typical within social interactions (Hull et al., 2017). These deliberate masking behaviors suggest that-rather than lacking motivation for relationships-autistic individuals may instead differ in their social skill and communication styles, struggle to have their social needs met, and expend tremendous 
effort trying to fit in (Hintzen et al., 2010; Chevallier et al., 2012b; Garman et al., 2016).

Collectively, this broad body of research has delineated reliable group-level differences between autistic and NA people on a range of social cognitive, social skill, and social motivation measures, with findings more variable and idiosyncratic concerning their association with social and functional outcomes. One potential reason for the lack of more established links with broader outcomes is that no studies have assessed whether and how these three social abilities relate to social interaction success or difficulties for autistic adults. Social interaction serves as the interface between the individual abilities and social outcomes, and despite social interaction difficulties constituting a core diagnostic component of autism, no research to our knowledge has systematically examined whether social cognition, social skill, and social motivation correspond to real-world social interaction outcomes for autistic adults. Critically, social interaction involves more than one person and necessitates consideration of not just an individual's social abilities, but also those of the interaction partner-and the relational combination between them-in order to understand how each partner influences the other (De Jaegher, 2013; Hehman et al., 2017). Research in autism, however, has focused overwhelmingly at the level of the individual, with studies of social interaction even being called a "blind spot" (De Jaegher, 2013) because so few studies have assessed dynamic interaction amongst and between autistic people.

This has started to change in recent years. Recent empirical work with autistic adults has shown that social interaction quality and positive perceptions are driven by relational factors to a greater degree than individual ones (Crompton et al., 2020; Morrison et al., 2020). For instance, autistic adults disclose more about themselves (Morrison et al., 2020), communicate more effectively, and establish better rapport (Crompton et al., 2020) when interacting with other autistic adults relative to NA adults. This suggests that relational compatibility, and not just individual characteristics, contribute to social interaction outcomes for autistic adults, but it remains unclear whether specific social abilities either individually or dyadically underlie this effect.

A previous study (Morrison et al., 2020) reported that autistic adults were evaluated less favorably by both autistic and NA partners after engaging in a real-world "get to know you" conversation, and NA adults expressed a preference for future social interaction with NA relative to autistic adults. In contrast, autistic adults trended toward preferring interaction with autistic relative to NA adults. The current study analyzes additional data from this sample to assess whether and how three aspects of social ability (i.e., social cognition, social skills, and social motivation) relate to social interaction outcomes for autistic and non-autistic adults across three dyadic combinations of diagnostic status (i.e., A-A, NA-NA, A-NA). The Actor-Partner Interdependence Model (APIM; Kenny et al., 2006) was used to assess the effect of individuals' social abilities on their own evaluations of their partner and the interaction (actor effects), the effect of the partners' social abilities on how individuals evaluate that partner and the interaction (partner effects), and the interaction between the two (actor-partner interactions). We predicted that (1) regardless of diagnosis, individuals with lower social cognitive performance, social motivation, and observed social skill will evaluate their partner less favorably and rate their own experience of the interactions lower in quality and closeness (i.e., actor effects); (2) regardless of diagnosis, individuals with lower social cognitive performance, social motivation, and observed social skill will be evaluated less favorably by their partners and their partners would rate their experience of the interactions lower in quality and closeness (i.e., partner effects); (3) actor, partner, and actor-partner interaction effects involving social variables will be moderated by diagnosis, such that effects of social abilities on outcomes will be stronger for autistic compared to NA individuals; and (4) actor, partner, and actor-partner interaction effects involving social variables will be moderated by dyad type, such that the effect of social abilities on outcomes will differ depending on whether dyads share or differ in their diagnostic status. Together, these hypotheses assess which factors predict person and interaction evaluations, and what combinations of partners and/or traits lead to poor or favorable interactions.

\section{METHODS}

\section{Participants}

One hundred and twenty-five adults (67 A, $58 \mathrm{NA}$ ) participated in one of three types of conversation dyads: A-A $(n=22)$, ANA $(n=25)$, and NA-NA $(n=23)$. Autistic participants were recruited from the UT Dallas Autism Research Collaborative, a research registry of clinically assessed autistic adults who have expressed interest in participating in university research studies. Inclusion in the registry requires confirmed diagnoses using the ADOS-II (Lord et al., 2000) and full-scale intelligent quotients (IQ) over 70 on the WASI-II (Wechsler, 2011), both of which occurred during a previous clinical intake session. Full-scale IQs over 90 were required for this study in order to be intellectually comparable to the NA participants. All included NA participants were university undergraduates, and only those who reported no history of psychiatric illness (8 excluded), no developmental disability (including autism; 1 excluded), and no autistic firstdegree relatives (4 excluded) were retained in the study. Those with autistic first-degree relatives were excluded to minimize inclusion of NA adults with high familiarity with autism and/or autistic traits. Additionally, two autistic adults were excluded for having an IQ lower than 70 . The protocol for the study was approved by the University Institutional Review Board, and all participants provided informed consent before the study began.

Autistic and NA participants were recruited with the intent of matching the diagnostic groups and the three dyad types demographically. All participants were male to avoid the complicating dynamics of inter-sex dyads and because the higher male ratio in autism (Fombonne, 2009) and in our recruitment sources precluded a well-powered examination of gender effects. Autistic and NA participants differed in age (A mean $=23.51$, $\mathrm{SD}=4.07 ; \mathrm{NA}$ mean $=20.84, \mathrm{SD}=3.17 ; p<0.01)$ but did not differ on race ( $\mathrm{A}=84 \%$ White; $\mathrm{NA}=81 \%$ White; $p=0.83$ ) and estimated IQ on the Wide Range Achievement Test (WRAT3; Wilkinson, 1993; A mean $=110.77, \mathrm{SD}=8.58$; $\mathrm{NA}$ mean $=$ 109.91, $\mathrm{SD}=8.39 ; p=0.58)$, a brief assessment that correlates highly with full scale IQ (Powell et al., 2002). The three dyad 
types did not differ on race $(p=0.97)$ or estimated IQ $(p=0.17)$, but did on age $(p<0.01)$, with the NA-NA group consisting of younger participants than the other two dyad types. To ensure that any findings between diagnostic groups and dyad types were not influenced by demographic characteristics, age, race, and IQ were covaried in all analyses. Demographic characteristics for the diagnostic and dyad groups can be viewed in Table 1. For more details about the sample, including information about the descriptive and psychometric properties of all included measures, see Morrison et al. (2020).

\section{Procedure}

Potential participants were initially screened for inclusion criteria, scheduling availability, and demographic characteristics. This information was then used to recruit unfamiliar dyadic partnerships of participants similar on age and race. Efforts to recruit unfamiliar conversation partners were largely successful: only one dyad consisted of partners who mutually acknowledged seeing their conversation partner previously, but both said that they had never spoken.

After providing informed consent, participants sat in chairs facing each other and were videotaped while completing an unstructured conversation developed to evaluate dyadic interaction (Berry and Hansen, 1996). This measure originally was created to measure interactions between two NA participants but recently similar paradigms have also been used with autistic adults (Usher et al., 2018; Morrison et al., 2020). Participants are told that they will be talking to their partner for $5 \mathrm{~min}$. No specific instructions are given other than telling them that their goal is to get to know the other person. After instructions were given, the experimenter moved behind a partition to avoid influencing the interaction. Participants were not explicitly made aware of the diagnostic status of their partners, but disclosure occurred organically during interactions within three A-A dyads and three A-NA dyads. Following the conversation, participants completed measures on separate computer stations that (1) recorded their impressions of the interaction and their conversation partner, (2) assessed their social cognitive performance, and (3) measured their social motivation. To ensure order effects did not influence results, these groups of measures were counterbalanced for each participant, and the order of the measures within each group of measures was randomized.

\section{Measures}

\section{Evaluation of the Partner and the Interaction}

Participants evaluated their conversation partner using the First Impression Scale for Autism (FIS; Sasson et al., 2017) and the International Personality Item Pool-Interpersonal Circumplex (IPIP-IPC; Markey and Markey, 2007) The FIS includes 10 items using a four-point scale. Participants rated their partner on six traits (awkwardness, attractiveness, trustworthiness, likability, dominance, and intelligence), and completed four items concerning their interest in socializing with their partner in the future (e.g., "I would hang out with this person in my free time"). Because the social interest items, but not the trait items, showed relatively high internal consistency (see Morrison et al., 2020 for details), a composite score averaging the four social interest items was used in analyses, whereas the six trait items were individually included.

The IPIP-IPC consists of 32 items assessing social behavioral characteristics unassessed by the FIS. Specifically, the IPIPIPC measures interpersonal warmth and dominance, two key predictors of dyadic behavior in social interactions and a variety of interaction outcomes [e.g., relationship satisfaction, task productivity, and liking (Markey and Markey, 2007; Markey et al., 2010)]. Items are aggregated to calculate separate warmth and dominance scores that are then used in analyses.

Participants evaluated qualities of the interaction using the Social Interaction Evaluation Measure (SIEM: Berry and Hansen, 1996), the Inclusion of Other in the Self (IOS Scale; Aron et al., 1997), and the Subjective Closeness Index (SCI; Berscheid et al., 1989). The SIEM is a self-report measure consisting of 11 questions rated on an eight-point scale concerning the participant's perceptions of the interaction quality, the intimacy of the interaction, the partner's level of disclosure, and the partner's level of engagement in the conversation. The items are averaged to create a composite score indicating overall interaction quality (Heerey and Kring, 2007).

The IOS and SCI are measures of interpersonal closeness that are averaged together to create an overall closeness composite score (Aron et al., 1997). The IOS requires the participant to select one of seven overlapping circles that best represents how close they feel to their conversation partner. The SCI uses a sevenpoint scale to ask the participant to rate their level of closeness to their partner relative to their other relationships and their perception of closeness in the relationships of other people.

\section{Evaluation of Social Abilities: Social Cognition, Social Motivation, and Social Skills \\ Social cognition}

Participants completed three measures spanning the separate domains of social cognition: face perception (Benton Facial Recognition Task; Benton et al., 1983), emotion recognition (Penn Emotion Recognition Task, ER-40; Kohler et al., 2000), and theory of mind (The Awareness of Social Inference Task. TASIT; McDonald et al., 2003). In the Benton, participants view 54 faces and select the matching face from an array of six faces. In the ER-40, participants select one of five emotion choices corresponding to the emotion expressed in 40 face photos. In the TASIT, participants watch 16 short videos depicting characters lying or being sarcastic within social interactions and answer four questions after each video regarding what the characters' intentions, thoughts, and beliefs were about the other people or the scenario. All three tasks have been used in previous studies of autism (Philip et al., 2010; Neves et al., 2011; Ratto et al., 2011) and have been psychometrically validated for inclusion in autism research (Morrison et al., 2019b). As has been done previously (Sasson et al., 2013), social cognitive scores from these three domains were standardized and averaged together to yield a total social cognition composite score used in primary analyses. The independent impact of each social cognition domain on social interaction outcomes was also pursued in exploratory analyses. 
TABLE 1 | Demographic characteristics for diagnostic and dyad groups.

\begin{tabular}{|c|c|c|c|c|}
\hline \multicolumn{3}{|c|}{ Dyad groups } & \multicolumn{2}{|c|}{ Overall } \\
\hline A-A & NA-NA & A-NA & A & NA \\
\hline$(n=42)$ & $(n=40)$ & $(n=42)$ & $(n=66)$ & $(n=58)$ \\
\hline
\end{tabular}

\begin{tabular}{|c|c|c|c|c|c|c|c|c|c|c|c|c|}
\hline \multicolumn{13}{|l|}{ Race } \\
\hline White & \multicolumn{2}{|c|}{36} & \multicolumn{2}{|c|}{33} & \multicolumn{4}{|c|}{34} & \multicolumn{2}{|c|}{56} & \multicolumn{2}{|c|}{47} \\
\hline Black & \multicolumn{2}{|c|}{2} & \multicolumn{2}{|c|}{2} & \multicolumn{4}{|c|}{2} & \multicolumn{2}{|c|}{3} & \multicolumn{2}{|c|}{3} \\
\hline \multirow[t]{2}{*}{ Other } & \multicolumn{2}{|c|}{2} & \multicolumn{2}{|c|}{4} & \multicolumn{4}{|c|}{4} & \multicolumn{2}{|c|}{4} & \multicolumn{2}{|c|}{6} \\
\hline & $M$ & $S D$ & $M$ & $S D$ & \multicolumn{2}{|c|}{ A } & \multicolumn{2}{|c|}{ NA } & $M$ & $S D$ & $M$ & $S D$ \\
\hline Age & 22.67 & 3.62 & 20.62 & 3.43 & 25.10 & 4.47 & 21.33 & 2.50 & 23.51 & 4.07 & 20.84 & 3.17 \\
\hline WRAT-3 IQ & 111.88 & 7.12 & 110.78 & 7.91 & 108.67 & 10.72 & 108.00 & 9.34 & 110.77 & 8.58 & 109.91 & 8.39 \\
\hline
\end{tabular}

WRAT-3, Wide Range Achievement Test 3rd Edition.

\section{Social motivation}

Participants completed the Friendship Motivation Scale (Richard and Schneider, 2005) to assess their interest in forming social relationships. Participants answer 12 questions on a 4-point scale across four subscales: intrinsic motivation, identified regulation, external regulation, and amotivation. Intrinsic motivation refers to self-determination for seeking friendships, in which social relationships are satisfying for internal reasons (e.g., for the pleasure I get by talking with friends). The other three types of motivation are extrinsic in nature. Identified regulation refers to seeking relationships for their own sake (e.g., because I think having friends is good for me). External regulation refers to seeking friendships for environmental reasons or rewards (e.g., to be invited to parties). Lastly, amotivation refers to a lack of motivation to seek friendships because the individual does not perceive benefits from friendships (e.g., I don't see why I would want to have friends). The total social motivation score was computed by summing weighted subscale scores, with higher scores signifying higher social motivation (see Richard and Schneider, 2005 for formula).

\section{Social skills}

To obtain a measure of both partners' social skills, three independent raters (one autistic) were trained on the Conversation Probe (CP) social behavior coding manual (Pinkham and Penn, 2006). Prior to coding, raters attended training sessions and coded videos until consensus in ratings was achieved on $20 \%$ of the videos. All raters were blind to participant diagnoses. The CP captures both discrete social skill ratings and a holistic rating of the participant's overall social skill. Coders first coded nine discrete behaviors categorized into four composite skill groups: appropriate content, paralinguistic behaviors, interactive behaviors, and non-verbal behaviors (Morrison et al., 2017). Conversational content refers to the participant's ability to discuss topics appropriate to meeting someone for the first time. Paralinguistic behaviors quantify the quality of participants' speech other than semantic content (e.g., speaking with clarity, enunciating clearly and fluently, and successfully switching turns with their partner). Interactive behaviors measure the degree to which participants are interested in getting to know their partners and carry on the interaction. This subscale was comprised of involvement, or the degree to which the participants appear engaged in the conversation, and the number of questions the participants asked of their partner. Lastly, non-verbal behaviors consisted of the degree of appropriate eye-contact and affective behaviors displayed by the participants. These social behaviors were originally derived based upon non-autistic norms, and thus the CP should be understood as measuring social skills considered normative and valued by non-autistic society.

Each social skill rating was made on a nine-point Likert scale, where higher scores indicated better social skills ability. Coders also make a holistic judgement of the participant's overall skill ability, rating how successful the participant was at interacting with his partner. Intraclass correlation coefficients (ICCs) were computed to assess reliability on the videos. The three coders' consistency ranged from 0.57 to 0.95 on the behaviors across the full sample of videos and they were strongly consistent for overall social skills (ICC $=0.732$ ). Reliability is displayed in Table 2 .

\section{Analysis Plan}

Before proceeding to our primary analyses, we inspected the descriptive statistics for the study variables and tested whether autistic and NA adults significantly differed in their respective group means. We then investigated the pattern of zero-order correlations between the study variables for autistic and NA adults separately to gain some preliminary insights into possible group differences in the predictor-predictor and predictoroutcome associations.

Because outcomes for partners were interrelated and thus non-independent, traditional analytic techniques (e.g., general linear model) could not be used for primary analyses. 
TABLE 2 | Means and group comparison of social skills.

\begin{tabular}{|c|c|c|c|c|c|c|c|}
\hline & \multirow[t]{2}{*}{ ICC } & \multicolumn{2}{|c|}{ A } & \multicolumn{2}{|c|}{ NA } & \multirow[t]{2}{*}{$F_{(1,123)}$} & \multirow[t]{2}{*}{$p$} \\
\hline & & $M$ & $S D$ & $M$ & $S D$ & & \\
\hline Content & 0.731 & 6.72 & 0.81 & 7.09 & 0.60 & 8.177 & 0.005 \\
\hline Clarity & 0.588 & 6.08 & 0.96 & 6.42 & 0.72 & 4.934 & 0.028 \\
\hline Fluency & 0.765 & 6.01 & 1.08 & 6.60 & 0.59 & 13.817 & $<0.001$ \\
\hline Meshing & 0.713 & 6.02 & 1.16 & 6.59 & 0.68 & 10.841 & 0.001 \\
\hline Gaze & 0.660 & 6.67 & 1.12 & 7.55 & 0.57 & 29.398 & $<0.001$ \\
\hline Involvement & 0.793 & 6.59 & 1.09 & 7.21 & 0.55 & 15.149 & $<0.001$ \\
\hline Asks questions & 0.951 & 3.76 & 2.66 & 5.61 & 2.42 & 16.297 & $<0.001$ \\
\hline Appropriate affect & 0.655 & 6.80 & 0.54 & 7.12 & 0.46 & 12.361 & 0.001 \\
\hline Flat affect & 0.712 & 5.85 & 1.00 & 6.27 & 0.82 & 6.548 & 0.012 \\
\hline Social anxiety & 0.725 & 6.01 & 0.97 & 6.78 & 0.64 & 27.012 & $<0.001$ \\
\hline Overall skill & 0.732 & 5.57 & 1.04 & 6.44 & 0.62 & 31.494 & $<0.001$ \\
\hline Repetitive verbal content & 0.566 & 6.79 & 0.77 & 7.18 & 0.42 & 11.688 & 0.001 \\
\hline Repetitive movement & 0.743 & 6.56 & 0.97 & 7.17 & 0.55 & 17.813 & $<0.001$ \\
\hline Verbosity & 0.905 & 6.36 & 1.85 & 6.40 & 1.13 & 0.022 & 0.882 \\
\hline Paralinguistic & - & 6.04 & 0.86 & 6.54 & 0.47 & 15.675 & $<0.001$ \\
\hline Non-verbal & - & 6.44 & 0.69 & 6.98 & 0.47 & 25.459 & $<0.001$ \\
\hline Interactive & - & 5.18 & 1.60 & 6.41 & 1.34 & 21.373 & $<0.001$ \\
\hline
\end{tabular}

ICC refers to Intraclass correlation coefficient for coders' reliability. Note the paralinguistic, non-verbal, and interactive behaviors are composite scores rather than coded items, and thus do not have ICCs.

Instead, the Actor-Partner Interdependence Model (APIM) for indistinguishable dyads was used (Kenny et al., 2006). The APIM provides estimates of actor effects (e.g., the effect of individuals' social abilities on their own interaction outcomes), partner effects (e.g., the effect of individuals' partners' social abilities on individuals' interaction outcomes), and (if researchers are interested) actor-partner interactions (e.g., how the effect of individuals' social abilities on their own interaction outcomes depends upon their partners' social abilities). Additionally, by collecting dyads that differed in their diagnostic composition, we could investigate whether effects differed for autistic adults compared to NA adults, as well as whether the particular combination of dyad members (i.e., A-A, A-NA, NA-NA) moderated any effects (Kraemer and Jacklin, 1979; Kenny et al., 1988). Figure 1 visually displays the model used for analysis.

APIMs were specified using multilevel modeling with Restricted Maximum Likelihood estimation in SPSS Version 25. Multilevel modeling is appropriate because participants and their interaction partners are nested within dyads. It also helps to account for missing data in the outcomes, which were minimal in this study. Actor IQ, race, and age were entered as co-variates in all analyses. To facilitate the interpretation of the coefficients in each of the APIM analyses, continuous predictors were grandmean centered and categorical predictors were effects coded (moreover, interaction terms assessing moderation were specified using these centered and effect-coded variables). An adjusted alpha of 0.01 was used as the threshold for statistical significance given the large number of tests; however, a more lenient alpha of 0.05 was used when significant interaction terms were followed up to increase our power to detect simple slopes once our more conservative threshold for detecting an interaction was reached.

\section{RESULTS}

\section{Descriptive Statistics}

Normality, skew, and kurtosis were within acceptable ranges for analyses. Skew and kurtosis values were below the absolute value of 2 for all measures, with two item-level exceptions: aggression/dominance and the behavioral intent composite from the first impression scale exceeded the kurtosis threshold but were still relatively normal in their distributions. Means and standard deviations for social cognitive tasks, social motivation, and social skills can be viewed in Tables 2, 3 [those for outcome measures (i.e., first impression scale, IPC warmth, IPC dominance, interaction quality, and closeness) appear in Morrison et al., 2020]. NA adults scored higher than autistic adults on the Benton $\left[F_{(1,177)}=26.37, p<0.001\right]$, TASIT $\left[F_{(1,117)}=14.98, p<0.001\right]$, FMS $\left[F_{(1,117)}=12.46, p=0.001\right]$, social cognition composite score $\left[F_{(1,117)}=26.02, p<0.001\right]$, overall social skills ratings $\left[F_{(1,123)}=31.49, p<0.001\right]$, but diagnostic groups did not differ on the ER-40 $\left[F_{(1,117)}=2.79\right.$, $p=0.10]$.

Social ability predictors were weakly to moderately correlated with one another (Table 4). Correlations between predictors and actor and partner outcomes showed that for autistic adults, several social abilities moderately predicted partner evaluations (Tables 5, 6). As can be seen in Table 5, for autistic adults, higher social motivation on the FMS was related to perceiving the partner as warmer, less aggressive/dominant, smarter, and having a stronger desire to have a conversation with their partner. ER-40 scores predicted stronger acceptance of living near the partner, but higher theory of mind performance on the TASIT was related to feeling less close to partners, perceiving the partner as less dominant, and having less desire hang out with their partners later. For NA adults, higher ER-40 scores predicted rating partners lower in warmth, and higher TASIT scores were related to perceiving the partner as less dominant and more trustworthy. Higher social motivation on the FMS was related to seeing the partner as more attractive. As can be seen in Table 6, autistic adults with better observed social skills were rated as less awkward, smarter, and having higher quality interactions, those with better theory of mind performance on the TASIT were rated as smarter, and those with higher emotion recognition scores on the ER-40 were rated less dominant and more awkward. For NA adults, those with higher Benton facial recognition scores were rated as warmer.

\section{Actor-Partner Interdependence Model (APIM) Analyses}

An initial model, detailed in Morrison et al. (2020), was run to assess the effect of the diagnostic status (A or NA) of the actor, partner, and the interaction between them on reports of social interaction quality, closeness, and first impressions of various traits. For the current study, this model was run with additional parameters to examine (a) if social abilities (i.e., social cognition, social motivation, and social skill) predicted social interaction 


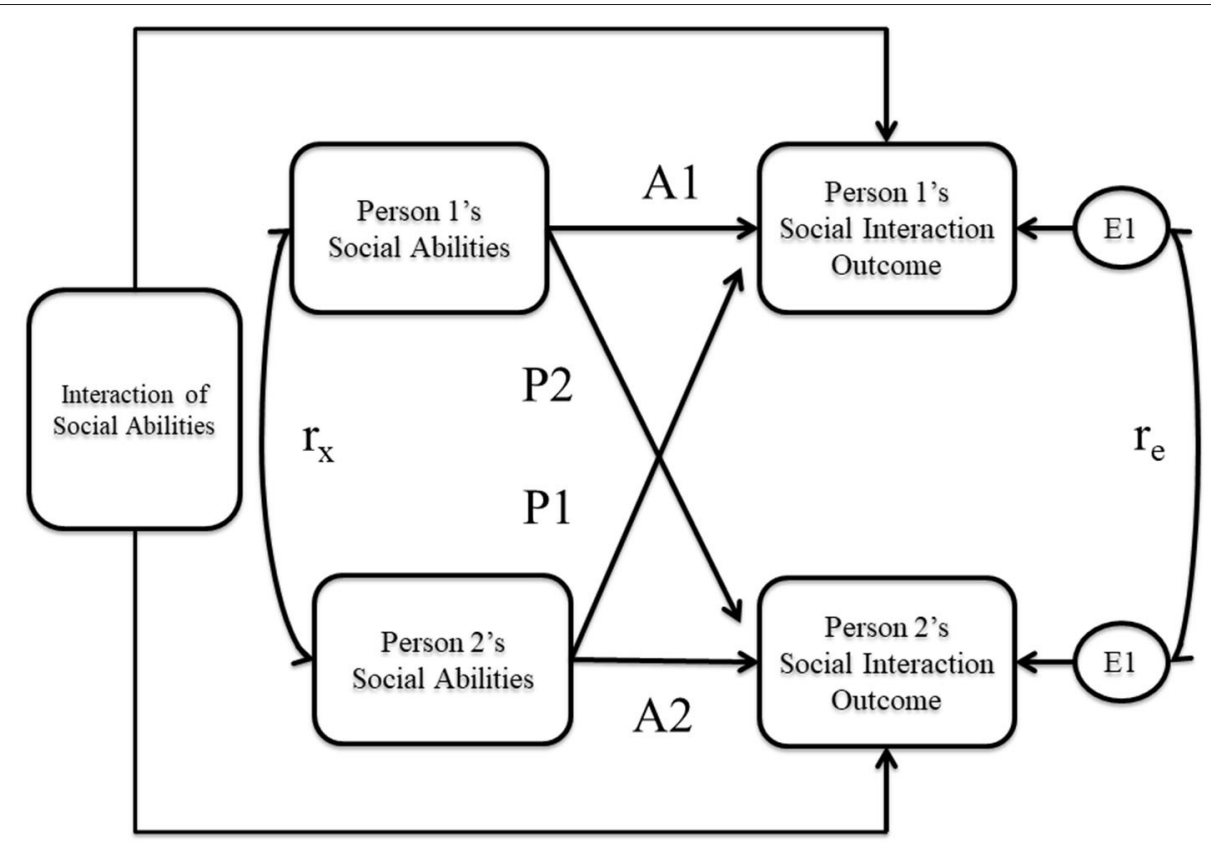

FIGURE 1 | Actor partner interdependence model (APIM) predicting social interaction outcomes with individual and partner social abilities. A-paths represent the actor effects and P-paths represent the partner effects. The interaction term represents the effect of the individual's social abilities on the individual's social interaction outcome depending on the partner's social abilities.

TABLE 3 | Scores on predictors for diagnostic and dyad groups.

\begin{tabular}{|c|c|c|c|c|c|c|c|c|c|c|c|c|}
\hline & \multicolumn{2}{|c|}{$\begin{array}{l}\text { A-A dyads } \\
(n=42)\end{array}$} & \multicolumn{2}{|c|}{$\begin{array}{l}\text { NA-NA dyads } \\
\qquad(n=40)\end{array}$} & \multicolumn{4}{|c|}{$\begin{array}{l}\text { A-NA dyads (A left; NA right) } \\
\qquad(n=42)\end{array}$} & \multicolumn{2}{|c|}{$\begin{array}{l}\text { A overall } \\
(n=66)\end{array}$} & \multicolumn{2}{|c|}{$\begin{array}{l}\text { NA overall } \\
(n=58)\end{array}$} \\
\hline & $M$ & $S D$ & $M$ & $S D$ & $M$ & $S D$ & $M$ & $S D$ & $M$ & $S D$ & $M$ & $S D$ \\
\hline Benton & 43.35 & 4.26 & 47.35 & 3.64 & 43.14 & 3.95 & 46.00 & 3.43 & 43.28 & 4.12 & 46.93 & 3.60 \\
\hline TASIT & 51.60 & 6.54 & 56.33 & 4.39 & 53.14 & 6.38 & 55.22 & 3.06 & 52.13 & 6.48 & 55.98 & 4.03 \\
\hline ER-40 & 34.08 & 2.49 & 34.73 & 2.72 & 33.52 & 2.73 & 34.56 & 2.28 & 33.89 & 2.57 & 34.67 & 2.57 \\
\hline Social Cog & -0.24 & 0.66 & 0.40 & 0.60 & -0.24 & 0.70 & 0.21 & 0.47 & -0.24 & 0.66 & 0.34 & 0.57 \\
\hline FMS & 15.35 & 7.15 & 19.40 & 5.29 & 16.33 & 7.16 & 20.33 & 4.45 & 15.69 & 7.11 & 19.69 & 5.02 \\
\hline Overall_SS & 5.71 & 1.00 & 6.35 & 0.63 & 5.67 & 0.96 & 6.65 & 0.56 & 5.57 & 1.04 & 6.44 & 0.62 \\
\hline
\end{tabular}

M, Mean; SD, Standard Deviation; ER-40, Emotion Recognition test; FMS, Friendship Motivation Scale; SS, Social Skills; TASIT, The Awareness of Social Inference Test.

outcomes, and (b) if these effects are moderated by diagnosis and dyad type (see Tables 7-15). Each of the tables focuses on a different set of social ability predictors and social interaction outcome variables. Whereas, Tables 7-9 includes APIM analyses with social evaluation measures as outcome variables, Tables 1015 include APIM analyses with first impression measures as outcome variables. Further, each table specifies the particular social ability variables being used as predictors (i.e., social cognitive, social skills, or social motivation).

For ease of presentation, we grouped the regression coefficients and standard errors for each set of predictors into different sections: (1) demographic variables, (2) diagnosis variables (i.e., the actor, partner, and actor-partner interaction effects for diagnostic status), (3) social ability variables (i.e., the actor, partner, and actor-partner interactions effects for the social ability variables), (4) moderation of the social ability variables by diagnosis variables (i.e., whether the actor, partner, and actor-partner interactions effects for the social ability variables depend upon the participants' or their partners' diagnostic status), and (5) moderation of the social ability variables by diagnostic combination or dyad type (i.e., whether the actor, partner, and actor-partner interactions effects for the social ability variables depend upon the diagnostic composition of the dyad). The regression coefficients and standard errors reflect the estimates from models wherein all predictors are included. Given the presence of multiple interaction terms, tolerance values (indices for multicollinearity) were rather low for the terms involving the social ability variables (mean values ranged from 0.26 for the social skill variables to 0.41 for the social motivation variables), moderation of the social ability variables 
TABLE 4 | Correlations between predictors.

\begin{tabular}{lccccc}
\hline & Benton & TASIT & ER-40 & FMS & Overall SS \\
\hline Benton & 1 & 0.017 & $0.361^{* \star}$ & -0.193 & 0.035 \\
TASIT & $0.272^{\star}$ & 1 & 0.221 & -0.24 & 0.122 \\
ER-40 & 0.121 & $0.308^{\star}$ & 1 & -0.009 & 0.196 \\
FMS & 0.129 & 0.166 & $0.278^{\star}$ & 1 & -0.037 \\
Overall SS & 0.06 & $0.335^{* *}$ & -0.137 & -0.025 & 1 \\
\hline
\end{tabular}

NA correlations are above diagonal and A below it. Predictors are actor social abilities. FMS, Friendship Motivation Scale; ER-40, Emotion Recognition task; SS, Social Skill; TASIT, The Awareness of Social Inference test. ${ }^{*} p<0.05,{ }^{*} p<0.01$.

by the diagnosis variables (mean values ranged from 0.25 for the social skill variables to 0.43 for the social motivation variables), and moderation of the social ability variables by diagnostic combination (mean values ranged from 0.26 for the social skill variables to 0.41 for the social motivation variables). Given our focus on the interaction terms, these tolerance values do not pose a problem (see McClelland et al., 2017).

\section{Effects of Social Cognition on Interaction Outcomes}

There were no significant actor, partner, or actor-partner interaction effects of social-cognition on any of the outcomes (see Tables 7, 10, 13). Nevertheless, we found a significant threeway interaction between actor diagnosis, partner diagnosis, and actor social cognition on interaction quality. To break this down, we inspected the simple two-way interactions between partner diagnosis and actor social cognition for autistic and NA participants. These analyses revealed an effect for NA actors ( $b$ $=1.13, \mathrm{SE}=0.43, p=0.01)$ but not autistic actors $(b=-0.26$, $\mathrm{SE}=0.19, p=0.18)$. Within A-NA dyads, NA actors with higher social cognitive performance rated the interaction quality higher $(b=1.80, \mathrm{SE}=0.72, p=0.014)$. However, this pattern was not observed for NA actors within NA-NA dyads $(b=-0.45, \mathrm{SE}=$ $0.43, p=0.30)$.

We also found a significant two-way interaction of actor diagnosis and partner social cognition on awkwardness scores. Autistic adults rated partners with higher social cognitive performance as more awkward than partners with lower social cognitive performance $(b=-0.65, \mathrm{SE}=0.27, p=0.02)$. This pattern was not observed for NA adults $(b=0.29, \mathrm{SE}=0.19$, $p=0.13$ ). However, this interaction was subsumed by a threeway interaction of actor and partner diagnosis and partner social cognitive ability. To break this down, we first inspected the simple two-way interactions of partner diagnosis and partner social cognition for autistic actors and for NA actors. The twoway interaction was significant for autistic actors $(b=0.61, \mathrm{SE}$ $=0.27, p=0.03)$ but not NA actors $(b=-0.31, \mathrm{SE}=0.19$, $p=0.10$ ). Further breaking down the two-way interaction for autistic actors revealed an effect of partner social cognition on autistic actors' awkwardness ratings in mixed dyads but not dyads of the same diagnosis. Specifically, whereas autistic actors rated their NA partners as more awkward when their partner had higher social cognitive performance $(b=-1.26, \mathrm{SE}=0.52, p$ $=0.02$ ), this effect was not seen for autistic actors in A-A dyads
TABLE 5 | Correlations between actor social abilities with actor outcomes.

\begin{tabular}{lccccc}
\hline NA & Benton & TASIT & ER-40 & FMS & $\begin{array}{c}\text { Overall social } \\
\text { skill }\end{array}$ \\
\hline Interaction quality & -0.068 & 0.058 & -0.014 & 0.141 & -0.048 \\
Closeness & 0.09 & -0.152 & -0.185 & 0.038 & -0.174 \\
IPC warmth & -0.159 & 0.096 & $-0.299^{\star}$ & 0.004 & -0.106 \\
IPC dominance & -0.141 & $-0.313^{\star}$ & -0.181 & -0.038 & 0.084 \\
Awkward_R & 0.039 & -0.085 & 0.041 & -0.034 & -0.064 \\
Attractive & -0.108 & 0.177 & 0.118 & $0.263^{\star}$ & 0.062 \\
Trustworthy & -0.214 & $0.300^{\star}$ & -0.147 & -0.077 & 0.008 \\
Aggressive/Dominant & -0.18 & -0.188 & 0.053 & 0.008 & -0.245 \\
Likable & -0.087 & 0.099 & -0.116 & 0.178 & -0.001 \\
Smart & -0.031 & 0.232 & 0.027 & 0.118 & 0.211 \\
Live near & -0.108 & 0.235 & -0.133 & 0.078 & 0.046 \\
Hangout & 0.208 & 0.178 & -0.064 & 0.153 & -0.039 \\
Sit near & -0.05 & 0.138 & -0.018 & 0.177 & -0.094 \\
Conversation & 0.256 & 0.202 & 0.071 & 0.166 & 0.232 \\
Behavioral Intent & 0.094 & $0.278^{\star}$ & -0.062 & 0.209 & 0.041 \\
A & & & & & \\
Interaction quality & 0.143 & 0.013 & -0.03 & 0.089 & -0.135 \\
Closeness & -0.093 & $-0.254^{\star}$ & -0.131 & 0.006 & 0.012 \\
IPC warmth & 0.019 & -0.053 & -0.166 & $0.409^{\star *}$ & -0.021 \\
IPC dominance & 0.062 & $-0.316^{\star}$ & -0.153 & -0.168 & 0.014 \\
Awkward_R & -0.16 & -0.105 & -0.096 & -0.026 & -0.126 \\
Attractive & 0.044 & 0.024 & 0.018 & -0.121 & 0.056 \\
Trustworthy & -0.128 & -0.051 & -0.173 & 0.049 & 0.15 \\
Aggressive/Dominant & 0.042 & 0.132 & 0.042 & $-0.243^{\star}$ & 0.22 \\
Likable & -0.087 & -0.190 & -0.052 & 0.081 & -0.006 \\
Smart & -0.059 & -0.015 & 0.135 & $0.290^{*}$ & -0.008 \\
Live near & 0.087 & 0.002 & $0.250^{\star}$ & 0.18 & 0.053 \\
Hangout & -0.149 & $-0.305^{\star}$ & -0.038 & 0.19 & -0.157 \\
Sit near & 0.111 & -0.004 & 0.131 & 0.232 & -0.049 \\
Conversation & 0.024 & -0.162 & -0.052 & $0.448^{\star *}$ & 0.037 \\
Behavioral intent & 0.039 & -0.150 & 0.127 & $0.366^{\star *}$ & -0.035 \\
\hline Outcones act & & & & & \\
\hline
\end{tabular}

Outcomes are actor ratings of the partner and interaction. Awkward was reverse scored. ER-40, Emotion Recognition task; FMS, Friendship Motivation Scale; IPC, Interpersonal Circumplex; TASIT, The Awareness of Social Inference test. ${ }^{*} p<0.05,{ }^{* *} p<0.01$.

$(b=-0.03, \mathrm{SE}=0.15, p=0.81)$. No other moderating effects were observed.

\section{Exploratory Analyses: Effects of Individual Social Cognitive Domains on Interaction Outcomes}

In addition to examining effects of the overall social cognition composite, we explored the effects of performance on each individual social cognitive task (i.e., Benton, ER40, TASIT). There were significant two-way interactions of actor and partner diagnosis with partner emotion recognition abilities (i.e., ER-40 scores) for trustworthiness ratings. Autistic actors trusted their partners more when their partners had higher levels of emotion recognition ability $(b=0.10, \mathrm{SE}=0.03, p=0.003)$. This effect was not significant for NA actors $(b=-0.03, \mathrm{SE}=0.03, p$ $=0.296$ ). Additionally, participants rated NA participants with stronger emotion recognition abilities as more trustworthy $(b=$ 
TABLE 6 | Correlations between actor predictors and partner outcomes.

\begin{tabular}{|c|c|c|c|c|c|}
\hline NA & Benton & TASIT & ER-40 & FMS & $\begin{array}{l}\text { Overall social } \\
\text { skill }\end{array}$ \\
\hline Interaction quality & 0.119 & 0.137 & 0.118 & -0.053 & 0.123 \\
\hline Closeness & 0.082 & 0.071 & 0.028 & -0.042 & 0.109 \\
\hline IPC warmth & $0.297^{\star}$ & 0.132 & 0.193 & 0.109 & 0.256 \\
\hline IPC dominance & 0.136 & 0.162 & 0.095 & 0.031 & 0.229 \\
\hline Awkward_R & 0.206 & 0.137 & 0.106 & -0.091 & 0.233 \\
\hline Attractive & -0.144 & -0.114 & 0.067 & 0.225 & 0.115 \\
\hline Trustworthy & 0.078 & -0.178 & 0.220 & 0.274 & -0.095 \\
\hline Aggressive/Dominant & -0.061 & 0.22 & -0.013 & 0.099 & -0.017 \\
\hline Likable & -0.120 & 0.105 & 0.027 & 0.041 & 0.096 \\
\hline Smart & -0.020 & -0.03 & 0.057 & 0.24 & -0.064 \\
\hline Live near & -0.053 & -0.035 & 0.009 & 0.163 & 0.043 \\
\hline Hangout & 0.079 & 0.145 & -0.102 & -0.051 & 0.129 \\
\hline Sit near & 0.035 & 0.068 & 0.150 & -0.071 & -0.220 \\
\hline Conversation & 0.204 & -0.153 & 0.013 & -0.09 & -0.005 \\
\hline Behavioral Intent & 0.073 & 0.026 & 0.025 & 0.001 & -0.017 \\
\hline \multicolumn{6}{|l|}{ A } \\
\hline Interaction quality & -0.013 & -0.004 & 0.010 & -0.063 & $0.260^{*}$ \\
\hline Closeness & 0.188 & 0.144 & 0.192 & 0.054 & 0.073 \\
\hline IPC warmth & 0.006 & 0.036 & 0.162 & -0.086 & 0.221 \\
\hline IPC dominance & 0.04 & -0.185 & $-0.267^{*}$ & -0.093 & 0.060 \\
\hline Awkward_R & 0.041 & 0.094 & $-0.262^{*}$ & -0.029 & $0.328^{\star}$ \\
\hline Attractive & -0.107 & 0.101 & -0.045 & -0.2 & 0.224 \\
\hline Trustworthy & -0.022 & -0.184 & -0.147 & 0.095 & 0.206 \\
\hline Aggressive/Dominant & 0.221 & -0.067 & -0.201 & 0.027 & 0.096 \\
\hline Likable & 0.074 & 0.059 & 0.150 & 0.026 & 0.059 \\
\hline Smart & 0.054 & $0.348^{\star \star}$ & 0.192 & 0.149 & $0.265^{\star}$ \\
\hline Live near & -0.029 & 0.063 & 0.142 & 0.168 & -0.147 \\
\hline Hangout & 0.22 & 0.22 & 0.023 & 0.058 & 0.149 \\
\hline Sit near & -0.081 & 0.033 & 0.070 & 0.189 & -0.045 \\
\hline Conversation & 0.041 & -0.047 & -0.071 & 0.135 & 0.227 \\
\hline Behavioral Intent & 0.047 & 0.109 & 0.079 & 0.234 & 0.052 \\
\hline
\end{tabular}

Outcomes are partner ratings of the actor and interaction. Awkward was reverse scored. ER-40, Emotion Recognition task; FMS, Friendship Motivation Scale; IPC, Interpersonal Circumplex; TASIT, The Awareness of Social Inference test. ${ }^{*} p<0.05,{ }^{* *} p<0.01$.

$0.09, \mathrm{SE}=0.03, p=0.006$ ), but this effect was not significant for autistic partners with differing levels of emotion recognition ability $(b=-0.04, \mathrm{SE}=0.03, p=0.15)$.

There were also significant two-way interactions for likeability. Autistic actors liked partners more when their partners had higher emotion recognition abilities $(b=0.09, \mathrm{SE}=$ $0.03, p=0.009)$, but this effect was not significant for NA actors $(b=-0.03, \mathrm{SE}=0.03, p=0.31)$. The interaction of partner diagnosis with facial recognition scores (i.e., Benton) was also significant $(p=0.002)$. Following up this interaction with simple slopes revealed that the effect of Benton scores on likeability ratings did not significantly differ from zero for both autistic and NA partners, but the pattern of effects suggests that participants rated higher likeability for NA partners who had lower facial recognition scores (NA partner: $b=-0.04, \mathrm{SE}=0.02, p=0.08$ ) and for autistic adults who had higher facial recognition scores (A partner: $b=0.03, \mathrm{SE}=0.02, p=0.08$ ).

\section{Effects of Social Skills on Interaction Outcomes}

There was a significant effect of the partner's composite social skills rating on awkwardness evaluations $(p<0.001)$, such that partners who were higher on observed social skills were rated as less awkward. No other actor, partner, or actor-partner interaction effects involving social skills were significant, and there was no evidence that diagnostic status or dyad type moderated any of these effects (see Tables 8, 11, 14).

\section{Effects of Social Motivation on Interaction Outcomes}

There were no significant actor, partner, or actor-partner interactions for the social motivation variables on any of the social interaction outcome variables (see Tables 9, 12, 15). However, there was a significant three-way interaction of actor and partner diagnoses with actor motivation scores on trustworthiness ratings $(p=0.007)$. To break this down, we examined the simple two-way interactions between partner diagnosis and actor social motivation for autistic and NA actors. There was a significant interaction of partner diagnosis with actor social motivation for NA actors $(b=-0.03$, SE $=0.02$, $p=0.03)$. NA actors with more social motivation rated their autistic partners as less trustworthy $(b=-0.06, \mathrm{SE}=0.03, p=$ $0.04)$, but this did not extend to NA partners $(b=0.01, \mathrm{SE}=$ $0.01, p=0.45)$. Moreover, the interaction of partner diagnosis and social motivation was marginally significant for autistic actors $(b=0.02, \mathrm{SE}=0.01, p=0.06)$. Breaking this two-way interaction down further revealed that autistic actors with more social motivation rated other autistic adults as marginally more trustworthy $(b=0.02, \mathrm{SE}=0.01, p=0.06)$, but this effect did not extend to NA partners $(b=-0.02, \mathrm{SE}=0.02, p=0.26)$.

\section{DISCUSSION}

In a previous study using this sample (Morrison et al., 2020), autistic adults were evaluated less favorably by unfamiliar partners following a "get to know you" conversation, and NA participants were less interested than autistic participants in interacting with them again in the future. In the current study, these autistic adults performed lower on a composite of social cognitive measures, were rated as less normative on social skills, and endorsed fewer normative indicators of social motivation compared to NA adults. All of these findings align with previous research (Chevallier et al., 2012a; Morrison et al., 2017, 2019a; Sasson et al., 2017; DeBrabander et al., 2019), but contrary to expectation, only minimal links were found between autistic adults' performance on the three social ability domains and their social interaction outcomes. In some cases, it was the social abilities of NA adults, not those of autistic adults, that were most predictive of outcomes, and this was particularly the case when they were interacting with autistic people. NA social cognition, for instance, predicted some of their interaction outcomes (e.g., awkwardness, interaction quality) with autistic but not NA partners. Collectively, findings suggest that standalone measures of autistic social abilities are not particularly predictive of 
TABLE 7 | Actor-partner interdependence model analyses estimating the combinatorial effects of diagnostic status and social cognition variables on the social evaluation outcomes of closeness, interaction quality, warmth, and dominance.

\begin{tabular}{|c|c|c|c|c|c|c|c|c|}
\hline \multirow{3}{*}{$\begin{array}{l}\text { Predictors } \\
\text { Social-cognition predictors }\end{array}$} & \multicolumn{8}{|c|}{ Social evaluation outcomes } \\
\hline & \multicolumn{2}{|c|}{ Closeness } & \multicolumn{2}{|c|}{ Interaction quality } & \multicolumn{2}{|c|}{ IPC warmth } & \multicolumn{2}{|c|}{ IPC dominance } \\
\hline & $b$ & SE & $b$ & SE & $b$ & SE & $b$ & SE \\
\hline Intercept & 2.92 & 0.23 & 5.70 & 0.18 & 0.03 & 0.17 & -0.03 & 0.20 \\
\hline \multicolumn{9}{|l|}{ Demographic variables } \\
\hline Actor WRAT & -0.02 & 0.01 & -0.01 & 0.01 & 0.01 & 0.01 & -0.01 & 0.01 \\
\hline Actor race-AfricanAmerican & -0.01 & 0.42 & 0.11 & 0.34 & 0.37 & 0.31 & 0.06 & 0.36 \\
\hline Actor race-Asian & 0.18 & 0.46 & -0.51 & 0.37 & -0.35 & 0.34 & -0.33 & 0.39 \\
\hline Actor race-Other & 0.05 & 0.34 & 0.52 & 0.29 & 0.09 & 0.27 & 0.32 & 0.31 \\
\hline Actor age & 0.05 & 0.03 & $0.06^{\star}$ & 0.02 & $0.06^{\star}$ & 0.02 & 0.02 & 0.03 \\
\hline \multicolumn{9}{|l|}{ Diagnosis variables } \\
\hline Actor diagnosis & 0.24 & 0.15 & -0.03 & 0.13 & -0.20 & 0.12 & -0.16 & 0.14 \\
\hline Partner diagnosis & -0.04 & 0.14 & -0.12 & 0.12 & -0.14 & 0.11 & -0.17 & 0.13 \\
\hline Actor Partner diagnosis & 0.19 & 0.16 & 0.12 & 0.13 & 0.03 & 0.12 & 0.03 & 0.14 \\
\hline \multicolumn{9}{|l|}{ Social cognition variables } \\
\hline Actor SC & -0.13 & 0.26 & 0.43 & 0.22 & 0.06 & 0.21 & -0.21 & 0.24 \\
\hline Partner SC & 0.38 & 0.26 & 0.13 & 0.22 & 0.40 & 0.21 & -0.15 & 0.24 \\
\hline Actor ${ }^{\star}$ Partner SC & -0.30 & 0.39 & 0.14 & 0.32 & 0.09 & 0.29 & 0.31 & 0.34 \\
\hline \multicolumn{9}{|c|}{ Moderation of social cognition variables by diagnosis variables } \\
\hline Actor diagnosis*Actor SC & -0.12 & 0.26 & -0.25 & 0.22 & -0.10 & 0.20 & -0.05 & 0.24 \\
\hline Actor diagnosis*Partner SC & 0.06 & 0.27 & -0.08 & 0.23 & 0.15 & 0.21 & -0.14 & 0.25 \\
\hline Actor diagnosis ${ }^{\star}\left(\right.$ Actor $^{\star}$ Partner SC) & -0.02 & 0.32 & -0.30 & 0.28 & -0.03 & 0.26 & 0.09 & 0.31 \\
\hline Partner diagnosis ${ }^{\star}$ Actor SC & -0.04 & 0.28 & 0.43 & 0.23 & 0.18 & 0.22 & 0.18 & 0.26 \\
\hline Partner diagnosis*Partner SC & -0.03 & 0.26 & -0.16 & 0.22 & -0.31 & 0.20 & -0.14 & 0.24 \\
\hline Partner diagnosis ${ }^{\star}\left(\right.$ Actor$^{\star}$ Partner SC) & -0.02 & 0.32 & 0.53 & 0.28 & 0.41 & 0.26 & 0.10 & 0.31 \\
\hline \multicolumn{9}{|c|}{ Moderation of social cognition variables by dyad type } \\
\hline (Actor ${ }^{\star}$ Partner diagnosis) ${ }^{\star}$ Actor SC & -0.22 & 0.28 & $-0.69^{\star \star}$ & 0.24 & -0.34 & 0.22 & -0.40 & 0.26 \\
\hline (Actor ${ }^{\star}$ Partner diagnosis) ${ }^{\star}$ Partner SC & -0.15 & 0.28 & -0.17 & 0.23 & -0.27 & 0.22 & 0.05 & 0.25 \\
\hline$\left(\text { Actor }{ }^{\star} \text { Partner diagnosis) }\right)^{\star}$ (ActorPartner SC) & -0.14 & 0.38 & -0.19 & 0.31 & -0.09 & 0.29 & 0.04 & 0.33 \\
\hline
\end{tabular}

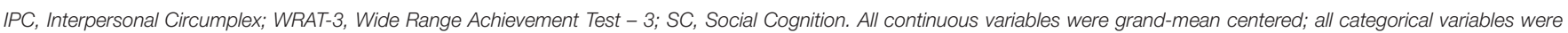

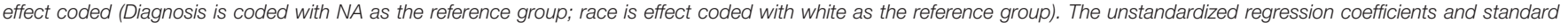
errors come from the corresponding full model in which all of the effects were included. ${ }^{*} p<0.05$, ${ }^{* *} p<0.01$.

their poorer interaction outcomes with NA partners. Rather, more consistent with relational accounts of autistic sociability (Milton, 2012; Bottema-Beutel, 2017; Bolis et al., 2018; Redcay and Schilbach, 2019), the dyadic combination of social abilities between diagnostic groups was more predictive of how autistic and NA adults evaluated (and were evaluated by) their partners.

Across the three social abilities assessed here, only normative social skill demonstrated any unidirectional predictive value on interaction outcomes. Most notably, those who were coded as less normative in their overall social skill were evaluated as more awkward. It may be the case that the overall social skill rating used here (Pinkham and Penn, 2006) is driven in part by the coder's perception of the person's awkwardness, which tended to align with participant evaluations of awkwardness within the dyads. This interpretation may explain why the social skill measure was associated with awkwardness ratings but not other evaluated traits: "awkwardness" may be consistent with an individual's judgment of another person's social skill, with lower ratings signifying a deviation from normative social expression and behavior. Perhaps not coincidently, NA raters in previous studies have tended to discriminate autistic and NA participants more on awkwardness than any other trait judgment (Grossman, 2015; Sasson et al., 2017; Sasson and Morrison, 2019), with awkwardness ratings highly associated with a reluctance among NA adults to pursue subsequent social interaction.

Autistic raters in this study also judged autistic people high on awkwardness, but unlike NA raters, this judgment was not associated with reduced social interest (Morrison et al., 2020). What underlies this dissociation remains unclear. Future research may seek to isolate the specific characteristics and cues driving higher scores of awkwardness and assess whether they may be interpreted and valued differently by autistic and NA people. For instance, recent findings suggest that autistic people may seek out interaction with those who present and communicate atypically (Granieri et al., 2020), as these differences-ones often described as "awkward" 
TABLE 8 | Actor-partner interdependence model analyses estimating the combinatorial effects of diagnostic status and social skills variables on the social evaluation outcomes of closeness, interaction quality, warmth, and dominance.

\begin{tabular}{|c|c|c|c|c|c|c|c|c|}
\hline \multirow{3}{*}{$\begin{array}{l}\text { Predictors } \\
\text { Social skills predictors }\end{array}$} & \multicolumn{8}{|c|}{ Social evaluation outcomes } \\
\hline & \multicolumn{2}{|c|}{ Closeness } & \multicolumn{2}{|c|}{ Interaction quality } & \multicolumn{2}{|c|}{ IPC warmth } & \multicolumn{2}{|c|}{ IPC dominance } \\
\hline & b & SE & b & SE & b & SE & b & SE \\
\hline Intercept & 2.90 & 0.24 & 5.86 & 0.21 & -0.04 & 0.20 & -0.23 & 0.22 \\
\hline \multicolumn{9}{|l|}{ Demographic variables } \\
\hline Actor WRAT & -0.02 & 0.01 & -0.01 & 0.01 & 0.00 & 0.01 & -0.01 & 0.01 \\
\hline Actor race - AfricanAmerican & 0.15 & 0.39 & 0.21 & 0.34 & 0.23 & 0.33 & -0.28 & 0.36 \\
\hline Actor race - Asian & 0.01 & 0.48 & -0.49 & 0.42 & -0.09 & 0.40 & -0.05 & 0.44 \\
\hline Actor race - Other & 0.05 & 0.33 & 0.53 & 0.29 & 0.04 & 0.28 & 0.42 & 0.32 \\
\hline Actor age & $0.06^{\star}$ & 0.03 & 0.04 & 0.03 & $0.06^{\star}$ & 0.02 & 0.00 & 0.03 \\
\hline \multicolumn{9}{|l|}{ Diagnosis variables } \\
\hline Actor diagnosis & 0.31 & 0.16 & -0.10 & 0.15 & -0.27 & 0.14 & 0.06 & 0.17 \\
\hline Partner diagnosis & -0.02 & 0.16 & 0.09 & 0.15 & -0.00 & 0.14 & -0.09 & 0.16 \\
\hline Actor ${ }^{\star}$ Partner diagnosis & 0.12 & 0.21 & -0.00 & 0.19 & 0.12 & 0.18 & 0.19 & 0.20 \\
\hline \multicolumn{9}{|l|}{ Social skills variables } \\
\hline Actor SS & -0.06 & 0.19 & -0.18 & 0.17 & -0.21 & 0.16 & 0.20 & 0.18 \\
\hline Partner SS & 0.28 & 0.19 & $0.38^{\star}$ & 0.17 & $0.38^{\star}$ & 0.16 & 0.29 & 0.19 \\
\hline Actor*Partner SS & -0.34 & 0.23 & -0.29 & 0.20 & 0.15 & 0.19 & 0.17 & 0.21 \\
\hline \multicolumn{9}{|c|}{ Moderation of social skills variables by diagnosis variables } \\
\hline Actor diagnosis ${ }^{\star}$ Actor SS & 0.08 & 0.22 & 0.17 & 0.19 & 0.02 & 0.18 & -0.18 & 0.20 \\
\hline Actor diagnosis*Partner SS & -0.25 & 0.21 & -0.22 & 0.19 & 0.07 & 0.18 & -0.13 & 0.20 \\
\hline Actor diagnosis ${ }^{\star}\left(\right.$ Actor $^{\star}$ Partner SS) & $0.40^{\star}$ & 0.19 & 0.16 & 0.18 & 0.12 & 0.17 & 0.10 & 0.19 \\
\hline Partner diagnosis*Actor SS & -0.09 & 0.21 & -0.13 & 0.18 & 0.17 & 0.17 & $0.42^{*}$ & 0.19 \\
\hline Partner diagnosis*Partner SS & -0.24 & 0.22 & 0.03 & 0.20 & -0.27 & 0.19 & -0.23 & 0.21 \\
\hline Partner diagnosis ${ }^{\star}\left(\right.$ Actor$^{\star}$ Partner SS) & 0.18 & 0.19 & 0.00 & 0.18 & -0.12 & 0.17 & 0.00 & 0.19 \\
\hline \multicolumn{9}{|c|}{ Moderation of social skills variables by dyad type } \\
\hline (ActorPartner diagnosis) ${ }^{\star}$ Actor SS & 0.14 & 0.19 & 0.02 & 0.17 & -0.03 & 0.16 & -0.29 & 0.18 \\
\hline (Actor ${ }^{\star}$ Partner diagnosis) ${ }^{\star}$ Partner SS & 0.34 & 0.19 & -0.06 & 0.17 & -0.13 & 0.16 & 0.02 & 0.19 \\
\hline (Actor*Partner diagnosis) $)^{\star}\left(\right.$ Actor ${ }^{\star}$ Partner SS) & 0.01 & 0.24 & 0.23 & 0.21 & -0.06 & 0.20 & -0.07 & 0.22 \\
\hline
\end{tabular}

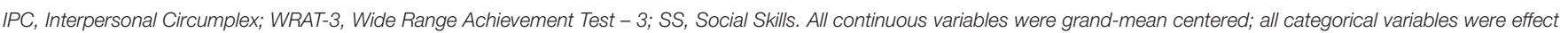

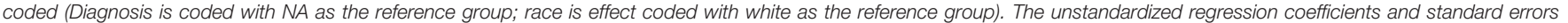
come from the corresponding full model in which all of the effects were included. ${ }^{*} p<0.05$.

- may cohere with their social preferences and facilitate better interpersonal communication and connection. Similarly, Heasman and Gillespie (2019) found that, contrary to normative expectations, misunderstanding, and misinterpretation among autistic adults did not invariably lead to deterioration of the interaction. Viewed through a conventional social lens, such disruptions may be perceived as awkward or seen as evidence of social disjunction, but these instances may be experienced differently by autistic adults. Perceptions of "awkwardness" therefore may reflect just one of many differences in social expectations and experiences between autistic and NA people.

Aside from ratings of awkwardness, normative social skill did not predict any trait evaluations or interaction outcomes for either the individual or their partner, was no more predictive of outcomes for autistic compared to NA adults, and did not vary across different dyad combinations. It may be the case that broader social judgments within a "get to know you" conversation depend less upon observable social skill and more upon other characteristics and considerations. For example, ratings of traits such as attractiveness may be influenced more by physical attributes rather than social behaviors, and judgments of likeability, trustworthiness, warmth, and interaction quality may be more related to conversational content, personal disclosure, and interpersonal alignment. Alternatively, or perhaps complementarily, conceptualizing social skill as an objective metric in which individuals can be quantitatively rank ordered and a single standard applied to all populations may be unhelpful for predicting complex social relationship dynamics, particularly between neurologically diverse people (Heerey, 2015; Bottema-Beutel, 2017; Milton, 2017). What constitutes good "social skill" may vary across groups and individuals, and a single holistic social skill rating may simply be inadequate for capturing and summarizing social skill across an entire dynamic and emergent interaction. Indeed, work examining interpersonal warmth and dominance suggests that moment to moment behaviors rather than overall summaries 


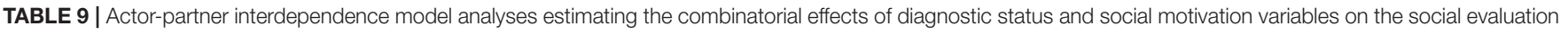
outcomes of closeness, interaction quality, warmth, and dominance.

\begin{tabular}{|c|c|c|c|c|c|c|c|c|}
\hline \multirow{3}{*}{$\begin{array}{l}\text { Predictors } \\
\text { Social motivation predictors }\end{array}$} & \multicolumn{8}{|c|}{ Social evaluation outcomes } \\
\hline & \multicolumn{2}{|c|}{ Closeness } & \multicolumn{2}{|c|}{ Interaction quality } & \multicolumn{2}{|c|}{ IPC warmth } & \multicolumn{2}{|c|}{ IPC dominance } \\
\hline & $b$ & SE & $b$ & SE & $b$ & SE & $b$ & SE \\
\hline Intercept & 2.87 & 0.24 & 5.78 & 0.21 & 0.11 & 0.16 & 0.04 & 0.22 \\
\hline \multicolumn{9}{|l|}{ Demographic variables } \\
\hline Actor WRAT & $-0.03^{\star}$ & 0.01 & -0.01 & 0.01 & 0.01 & 0.01 & $-0.02^{\star}$ & 0.01 \\
\hline Actor race - AfricanAmerican & 0.32 & 0.40 & 0.08 & 0.34 & 0.28 & 0.27 & -0.04 & 0.36 \\
\hline Actor race - Asian & 0.05 & 0.45 & -0.43 & 0.39 & -0.21 & 0.30 & -0.23 & 0.40 \\
\hline Actor race - Other & -0.18 & 0.33 & $0.67^{\star}$ & 0.30 & 0.17 & 0.25 & 0.39 & 0.32 \\
\hline Actor age & $0.05^{\star}$ & 0.03 & 0.04 & 0.02 & $0.05^{\star}$ & 0.02 & -0.00 & 0.03 \\
\hline \multicolumn{9}{|l|}{ Diagnosis variables } \\
\hline Actor diagnosis & $0.35^{\star \star}$ & 0.12 & 0.16 & 0.11 & -0.06 & 0.10 & -0.00 & 0.13 \\
\hline Partner diagnosis & -0.12 & 0.12 & -0.16 & 0.11 & -0.16 & 0.10 & -0.09 & 0.12 \\
\hline Actor ${ }^{\star}$ Partner diagnosis & 0.23 & 0.14 & 0.13 & 0.12 & 0.10 & 0.10 & -0.03 & 0.13 \\
\hline \multicolumn{9}{|l|}{ Social motivation variables } \\
\hline Actor SM & 0.02 & 0.02 & 0.03 & 0.02 & 0.02 & 0.02 & -0.00 & 0.02 \\
\hline Partner SM & 0.01 & 0.02 & -0.02 & 0.02 & -0.00 & 0.02 & -0.02 & 0.02 \\
\hline ActorPartner SM & 0.01 & 0.00 & 0.00 & 0.00 & -0.00 & 0.00 & 0.00 & 0.00 \\
\hline \multicolumn{9}{|c|}{ Moderation of social motivation variables by diagnosis variables } \\
\hline Actor diagnosisActor SM & -0.01 & 0.02 & -0.02 & 0.02 & 0.00 & 0.02 & 0.01 & 0.02 \\
\hline Actor diagnosisPartner SM & -0.00 & 0.02 & 0.01 & 0.02 & 0.00 & 0.02 & -0.01 & 0.02 \\
\hline Actor diagnosis ${ }^{\star}\left(\right.$ Actor ${ }^{\star}$ Partner SM) & -0.00 & 0.00 & 0.00 & 0.00 & 0.00 & 0.00 & -0.00 & 0.00 \\
\hline Partner diagnosis*Actor SM & 0.02 & 0.02 & 0.00 & 0.02 & $0.04^{\star}$ & 0.02 & -0.01 & 0.02 \\
\hline Partner diagnosisPartner SM & 0.02 & 0.02 & 0.00 & 0.02 & -0.02 & 0.02 & 0.00 & 0.02 \\
\hline Partner diagnosis *(ActorPartner SM) & 0.00 & 0.00 & 0.00 & 0.00 & 0.00 & 0.00 & 0.01 & 0.00 \\
\hline \multicolumn{9}{|c|}{ Moderation of social motivation variables by dyad type } \\
\hline (Actor ${ }^{\star}$ Partner diagnosis) $)^{\star}$ Actor SM & -0.02 & 0.02 & -0.00 & 0.02 & 0.02 & 0.02 & 0.00 & 0.02 \\
\hline 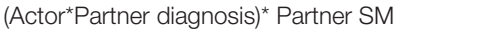 & -0.00 & 0.02 & 0.01 & 0.02 & -0.01 & 0.02 & 0.04 & 0.02 \\
\hline (Actor $^{\star}$ Partner diagnosis) ${ }^{\star}$ (Actor ${ }^{\star}$ Partner SM) & -0.00 & 0.00 & -0.00 & 0.00 & -0.00 & 0.00 & -0.00 & 0.00 \\
\hline
\end{tabular}

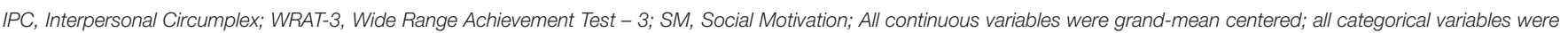

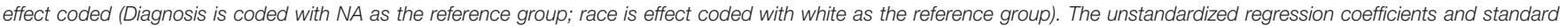
errors come from the corresponding full model in which all of the effects were included. ${ }^{*} p<0.05$, ${ }^{* *} p<0.01$.

are better predictors of interaction outcomes (Markey et al., 2010; Stevanovic et al., 2017).

Autistic adults' social cognitive performance was also not particularly predictive of their interaction outcomes. In fact, within mixed dyads, it was the social cognitive performance of NA adults, not autistic adults, that generated most of the effects. For instance, better social cognitive performance among NA adults was associated with rating conversations with autistic partners as higher in quality. One possible interpretation is that social cognitive ability among NA adults may facilitate better perception of social cues from their autistic partners and mitigate the difficulties NA people often have inferring autistic mental states (Edey et al., 2016; Sheppard et al., 2016; Gernsbacher et al., 2017). This also suggests that interaction quality between autistic and NA adults may improve by increasing social cognitive ability among NA people-perhaps more so than among autistic people given that no corresponding effect was found for autistic participants. Indeed, some emerging evidence indicates that NA observers who are better able to infer autistic mental states (Alkhaldi et al., 2019) and have greater understanding about autism (Sasson and Morrison, 2019) evaluate autistic people more favorably, suggesting that social experiences of autistic people within NA environments may improve with greater NA understanding about autism. Less provocatively, higher social cognitive performance among NA adults in this study may have been a proxy for other characteristics associated with more enjoyable conversational experiences with autistic partners, like higher social engagement, attentiveness, and desire for connection. Regardless of interpretation, however, this finding of NA social cognition predicting outcomes with autistic partners was not hypothesized and should therefore be interpreted cautiously until replicated.

Although NA adults with higher social cognitive performance rated conversations with autistic partners as higher in quality, autistic participants did not share this assessment and instead actually perceived NA adults who scored better on social 
TABLE 10 | Actor-partner interdependence model analyses estimating the combinatorial effects of diagnostic status and social cognition variables on the first impression variables of behavioral intent, awkwardness (reversed), attractiveness, and trustworthiness.

\begin{tabular}{|c|c|c|c|c|c|c|c|c|}
\hline \multirow{3}{*}{$\begin{array}{l}\text { Predictors } \\
\text { Social-cognition predictors }\end{array}$} & \multicolumn{8}{|c|}{ First-impression outcome variables } \\
\hline & \multicolumn{2}{|c|}{ Behavioral intent } & \multicolumn{2}{|c|}{$\begin{array}{l}\text { Awkwardness } \\
\text { (reverse scored) }\end{array}$} & \multicolumn{2}{|c|}{ Attractiveness } & \multicolumn{2}{|c|}{ Trustworthiness } \\
\hline & $\boldsymbol{b}$ & SE & $\boldsymbol{b}$ & SE & $\boldsymbol{b}$ & SE & $b$ & SE \\
\hline Intercept & 3.09 & 0.09 & 3.03 & 0.12 & 2.51 & 0.16 & 3.42 & 0.09 \\
\hline \multicolumn{9}{|l|}{ Demographic variables } \\
\hline Actor WRAT & 0.00 & 0.00 & -0.01 & 0.01 & 0.01 & 0.01 & 0.00 & 0.01 \\
\hline Actor race - AfricanAmerican & 0.13 & 0.17 & 0.32 & 0.22 & 0.11 & 0.30 & 0.04 & 0.17 \\
\hline Actor race - Asian & -0.36 & 0.18 & -0.24 & 0.24 & -0.04 & 0.32 & 0.15 & 0.18 \\
\hline Actor race - Other & 0.27 & 0.14 & 0.03 & 0.21 & -0.00 & 0.24 & 0.05 & 0.15 \\
\hline Actor age & $0.03^{*}$ & 0.01 & 0.02 & 0.02 & 0.03 & 0.02 & -0.00 & 0.01 \\
\hline \multicolumn{9}{|l|}{ Diagnosis variables } \\
\hline Actor diagnosis & -0.04 & 0.06 & 0.06 & 0.09 & 0.08 & 0.11 & -0.08 & 0.06 \\
\hline Partner diagnosis & -0.03 & 0.06 & $-0.28^{\star \star}$ & 0.09 & -0.16 & 0.10 & -0.07 & 0.06 \\
\hline Actor ${ }^{\star}$ Partner diagnosis & $0.14^{\star}$ & 0.07 & -0.03 & 0.09 & -0.08 & 0.12 & 0.06 & 0.07 \\
\hline \multicolumn{9}{|l|}{ Social cognition variables } \\
\hline Actor SC & 0.08 & 0.11 & 0.15 & 0.16 & 0.32 & 0.19 & -0.16 & 0.11 \\
\hline Partner SC & 0.02 & 0.11 & -0.18 & 0.16 & 0.02 & 0.19 & -0.06 & 0.11 \\
\hline Actor ${ }^{\star}$ Partner SC & 0.15 & 0.16 & -0.01 & 0.21 & 0.08 & 0.28 & 0.06 & 0.16 \\
\hline \multicolumn{9}{|c|}{ Moderation of social cognition variables by diagnosis variables } \\
\hline Actor diagnosis*Actor SC & -0.09 & 0.11 & -0.32 & 0.16 & -0.25 & 0.19 & 0.08 & 0.11 \\
\hline Actor diagnosis*Partner SC & 0.11 & 0.11 & $-0.47^{\star \star}$ & 0.17 & -0.13 & 0.20 & 0.13 & 0.12 \\
\hline Actor diagnosis ${ }^{\star}\left(\right.$ Actor $^{\star}$ Partner SC) & -0.10 & 0.14 & -0.03 & 0.21 & -0.01 & 0.23 & -0.18 & 0.14 \\
\hline Partner diagnosis*Actor SC & 0.17 & 0.12 & 0.29 & 0.17 & 0.12 & 0.20 & 0.06 & 0.12 \\
\hline Partner diagnosis*Partner SC & -0.03 & 0.11 & 0.15 & 0.16 & -0.03 & 0.19 & -0.14 & 0.11 \\
\hline Partner diagnosis ${ }^{\star}\left(\right.$ Actor $^{\star}$ Partner SC) & $0.28^{*}$ & 0.14 & $0.50^{*}$ & 0.21 & 0.05 & 0.23 & 0.08 & 0.14 \\
\hline \multicolumn{9}{|c|}{ Moderation of social cognition variables by dyad type } \\
\hline (Actor ${ }^{\star}$ Partner diagnosis) ${ }^{\star}$ Actor SC & -0.09 & 0.12 & -0.10 & 0.17 & -0.26 & 0.20 & -0.00 & 0.12 \\
\hline (Actor $^{\star}$ Partner diagnosis)*Partner SC & -0.02 & 0.12 & $0.46^{\star \star}$ & 0.17 & 0.08 & 0.20 & -0.09 & 0.12 \\
\hline 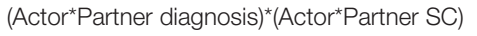 & -0.07 & 0.15 & 0.14 & 0.20 & -0.34 & 0.27 & -0.06 & 0.15 \\
\hline
\end{tabular}

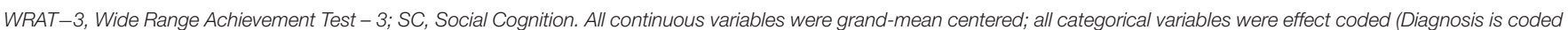

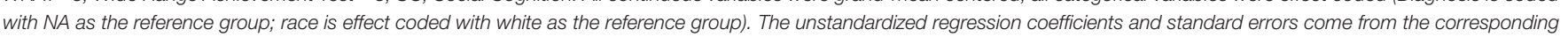
full model in which all of the effects were included. ${ }^{\star} p<0.05,{ }^{* *} p<0.01$.

cognitive measures as more awkward than those who scored lower. At first blush, this finding appears counterintuitive and potentially spurious, but the strict alpha level reduces the likelihood that this is the case. What underlies this effect is unclear, but it may be the case that social cognitive ability among NA individuals manifests in social behaviors perceived as awkward or intrusive by autistic adults. Alternatively, as suggested previously, autistic individuals may interpret the term "awkward" differently than NA individuals, but other findings suggest that autistic adults did perceive "awkward" as a negative characteristic - their ratings of awkwardness were related to lower intentions to interact as well as with other less favorable trait evaluations. Importantly, however, these relationships were weaker than those found for NA adults.

Additionally, despite performing lower on several social cognitive tasks, autistic adults largely mirrored NA adults in forming less favorable evaluations of other autistic adults
(Morrison et al., 2020). Thus, contrary to what might be expected based on their lower social cognitive performance, autistic adults appeared just as sensitive to social presentation differences among autistic adults and interpreted these differences similarly to their NA counterparts. Additionally, autistic adults rated partners who were more skilled in emotion recognition ability as more trustworthy and likable. This suggests that despite performing less well on standalone social cognitive tasks, interacting with someone skilled in these domains improved how autistic adults perceived their partner. Taken together, these findings suggest that the lower social cognitive performance demonstrated by autistic adults did not correspond in clear and predictable ways to their real-world social interaction outcomes. Isolated computerized assessments of social cognition such as those used here may not fully capture how these social abilities influence actual social interaction. This does not mean that these measures fail to capture social cognitive 
TABLE 11 | Actor-partner interdependence model analyses estimating the combinatorial effects of diagnostic status and social skills variables on the first impression variables of behavioral intent, awkwardness (reversed), attractiveness, and trustworthiness.

\begin{tabular}{|c|c|c|c|c|c|c|c|c|}
\hline \multirow{3}{*}{$\begin{array}{l}\text { Predictors } \\
\text { Social skills predictors }\end{array}$} & \multicolumn{8}{|c|}{ First-impression outcome variables } \\
\hline & \multicolumn{2}{|c|}{ Behavioral intent } & \multicolumn{2}{|c|}{$\begin{array}{l}\text { Awkwardness } \\
\text { (reverse scored) }\end{array}$} & \multicolumn{2}{|c|}{ Attractiveness } & \multicolumn{2}{|c|}{ Trustworthiness } \\
\hline & $\boldsymbol{b}$ & SE & $\boldsymbol{b}$ & SE & $\boldsymbol{b}$ & SE & $b$ & SE \\
\hline Intercept & 3.09 & 0.10 & 2.98 & 0.13 & 2.60 & 0.17 & 3.48 & 0.10 \\
\hline \multicolumn{9}{|l|}{ Demographic variables } \\
\hline Actor WRAT & 0.00 & 0.01 & -0.01 & 0.01 & 0.01 & 0.01 & 0.01 & 0.01 \\
\hline Actor race - AfricanAmerican & 0.20 & 0.16 & -0.06 & 0.22 & 0.05 & 0.28 & 0.19 & 0.17 \\
\hline Actor race - Asian & -0.30 & 0.20 & -0.21 & 0.27 & -0.27 & 0.34 & 0.13 & 0.20 \\
\hline Actor race - Other & 0.15 & 0.14 & 0.25 & 0.20 & 0.21 & 0.23 & -0.12 & 0.15 \\
\hline Actor age & 0.02 & 0.01 & 0.01 & 0.02 & 0.02 & 0.02 & -0.01 & 0.01 \\
\hline \multicolumn{9}{|l|}{ Diagnosis variables } \\
\hline Actor diagnosis & 0.05 & 0.08 & -0.08 & 0.13 & -0.03 & 0.12 & 0.10 & 0.08 \\
\hline Partner diagnosis & -0.06 & 0.07 & -0.18 & 0.12 & -0.04 & 0.12 & -0.14 & 0.08 \\
\hline Actor ${ }^{\star}$ Partner diagnosis & 0.09 & 0.09 & 0.06 & 0.12 & -0.25 & 0.15 & -0.09 & 0.09 \\
\hline \multicolumn{9}{|l|}{ Social skills variables } \\
\hline Actor SS & 0.03 & 0.08 & -0.08 & 0.13 & 0.00 & 0.13 & 0.04 & 0.09 \\
\hline Partner SS & 0.01 & 0.08 & $0.38^{\star \star}$ & 0.13 & 0.21 & 0.13 & -0.07 & 0.09 \\
\hline Actor ${ }^{\star}$ Partner SS & -0.17 & 0.09 & -0.04 & 0.13 & -0.17 & 0.16 & -0.07 & 0.10 \\
\hline \multicolumn{9}{|c|}{ Moderation of social skills variables by diagnosis variables } \\
\hline Actor diagnosis*Actor SS & -0.02 & 0.09 & -0.04 & 0.13 & 0.11 & 0.15 & 0.08 & 0.10 \\
\hline Actor diagnosis ${ }^{\star}$ Partner SS & -0.07 & 0.09 & 0.02 & 0.13 & -0.29 & 0.15 & -0.10 & 0.10 \\
\hline Actor diagnosis ${ }^{\star}$ (Actor ${ }^{\star}$ Partner SS) & -0.03 & 0.09 & 0.09 & 0.14 & 0.26 & 0.14 & -0.08 & 0.09 \\
\hline Partner diagnosis*Actor SS & -0.02 & 0.09 & 0.03 & 0.13 & -0.23 & 0.15 & -0.04 & 0.09 \\
\hline Partner diagnosis*Partner SS & 0.01 & 0.09 & -0.09 & 0.14 & 0.22 & 0.16 & 0.11 & 0.10 \\
\hline Partner diagnosis *(Actor*Partner SS) & 0.05 & 0.09 & -0.00 & 0.14 & -0.06 & 0.14 & 0.06 & 0.09 \\
\hline \multicolumn{9}{|c|}{ Moderation of social skills variables by dyad type } \\
\hline (Actor ${ }^{\star}$ Partner diagnosis) ${ }^{\star}$ Actor SS & -0.01 & 0.08 & -0.00 & 0.13 & 0.17 & 0.13 & -0.10 & 0.09 \\
\hline$\left(\right.$ Actor ${ }^{\star}$ Partner diagnosis) ${ }^{\star}$ Partner SS & 0.06 & 0.08 & -0.03 & 0.13 & -0.00 & 0.13 & 0.11 & 0.09 \\
\hline$\left(\text { Actor }^{\star} \text { Partner diagnosis) }\right)^{\star}$ (Actor ${ }^{\star}$ Partner SS) & 0.05 & 0.10 & -0.07 & 0.13 & 0.23 & 0.17 & 0.02 & 0.10 \\
\hline
\end{tabular}

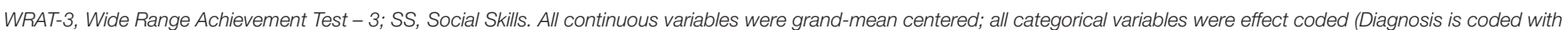

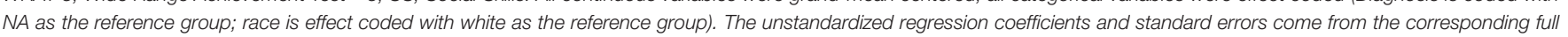
model in which all of the effects were included. ${ }^{\star \star} p<0.01$.

differences; in fact, as in previous research (Morrison et al., 2019b), they differentiated autistic and NA participants and were somewhat predictive of NA outcomes. Nevertheless, current findings raise questions about the mechanistic link between reduced social cognitive performance by autistic adults on standalone tasks and their difficulties interacting with NA adults. Recognizing faces and emotions from static images may not translate in presumed ways to the much more complex nature of dynamic interaction, even within NA-NA interactions. Similarly, higher social cognitive performance by NA adults did not facilitate better mutual interaction quality or an increase in shared positive outcomes with autistic adults. Collectively, such findings are consistent with double empathy (Milton, 2012) and dialectical misattunement (Bolis et al., 2018) theories of social disconnection between autistic and NA people and suggest that traditional conceptualizations of social cognitive ability may not extend in anticipated ways to autistic-NA interactions.
For social motivation, moderated results suggested lower social motivation scores among autistic participants did not impact how they were evaluated in the conversation. Indeed, there was only one group effect of social motivation, such that NA adults high on social motivation trusted their autistic partners less. It may be the case that socially motivated NA adults strive but struggle to connect with their autistic partners and misinterpret autistic social differences as indicative of lower trustworthiness. If so, this process could have adverse consequences for the social experiences of autistic adults, whose differences in social expressivity could be misperceived in ways that reinforce reluctance of NA adults to interact with them. Such an interpretation, however, is currently speculative and worthy of verification in future study.

Taken together, results from this study challenge traditional thinking about the mechanisms of social interaction difficulties 


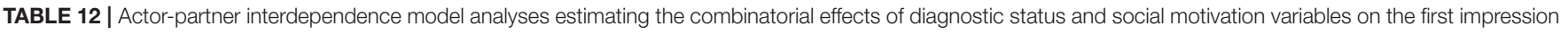
variables of behavioral intent, awkwardness (reversed), attractiveness, and trustworthiness.

\begin{tabular}{|c|c|c|c|c|c|c|c|c|}
\hline \multirow{3}{*}{$\begin{array}{l}\text { Predictors } \\
\text { Social Motivation Predictors }\end{array}$} & \multicolumn{8}{|c|}{ First-impression outcome variables } \\
\hline & \multicolumn{2}{|c|}{ Behavioral intent } & \multicolumn{2}{|c|}{$\begin{array}{l}\text { Awkwardness } \\
\text { (reverse scored) }\end{array}$} & \multicolumn{2}{|c|}{ Attractiveness } & \multicolumn{2}{|c|}{ Trustworthiness } \\
\hline & $\boldsymbol{b}$ & SE & $b$ & SE & $\boldsymbol{b}$ & SE & $\boldsymbol{b}$ & SE \\
\hline Intercept & 3.09 & 0.09 & 3.14 & 0.14 & 2.55 & 0.16 & 3.48 & 0.09 \\
\hline \multicolumn{9}{|l|}{ Demographic variables } \\
\hline Actor WRAT & 0.00 & 0.00 & -0.01 & 0.01 & 0.01 & 0.01 & 0.01 & 0.00 \\
\hline Actor race - AfricanAmerican & 0.17 & 0.15 & -0.00 & 0.23 & -0.11 & 0.26 & 0.03 & 0.15 \\
\hline Actor race - Asian & -0.31 & 0.16 & -0.15 & 0.26 & 0.08 & 0.30 & 0.30 & 0.16 \\
\hline Actor race - Other & 0.20 & 0.13 & 0.22 & 0.21 & 0.20 & 0.23 & -0.04 & 0.14 \\
\hline Actor age & 0.02 & 0.01 & 0.02 & 0.02 & 0.02 & 0.02 & -0.00 & 0.01 \\
\hline \multicolumn{9}{|l|}{ Diagnosis variables } \\
\hline Actor diagnosis & 0.06 & 0.05 & 0.10 & 0.09 & 0.07 & 0.09 & -0.02 & 0.06 \\
\hline Partner diagnosis & -0.03 & 0.05 & $-0.43^{\star \star}$ & 0.09 & $-0.20^{\star}$ & 0.08 & 0.02 & 0.05 \\
\hline Actor Partner diagnosis & $0.13^{\star}$ & 0.05 & -0.01 & 0.08 & -0.03 & 0.09 & -0.03 & 0.05 \\
\hline \multicolumn{9}{|l|}{ Social motivation variables } \\
\hline Actor SM & $0.02^{\star}$ & 0.01 & 0.01 & 0.02 & 0.01 & 0.01 & -0.01 & 0.01 \\
\hline Partner SM & 0.00 & 0.01 & -0.03 & 0.02 & -0.01 & 0.01 & 0.01 & 0.01 \\
\hline Actor Partner SM & 0.00 & 0.00 & -0.00 & 0.00 & $-0.01^{\star}$ & 0.00 & $-0.00^{\star}$ & 0.00 \\
\hline \multicolumn{9}{|c|}{ Moderation of social motivation variables by diagnosis variables } \\
\hline Actor diagnosis*Actor SM & -0.00 & 0.01 & -0.00 & 0.01 & -0.03 & 0.02 & 0.01 & 0.01 \\
\hline Actor diagnosis ${ }^{\star}$ Partner SM & 0.01 & 0.01 & -0.01 & 0.01 & -0.02 & 0.02 & 0.00 & 0.01 \\
\hline Actor diagnosis ${ }^{\star}\left(\right.$ Actor $^{\star}$ Partner SM) & 0.00 & 0.00 & -0.00 & 0.00 & -0.00 & 0.00 & 0.00 & 0.00 \\
\hline Partner diagnosis*Actor SM & 0.00 & 0.01 & 0.01 & 0.01 & -0.01 & 0.02 & -0.01 & 0.01 \\
\hline Partner diagnosis*Partner SM & -0.00 & 0.01 & 0.01 & 0.01 & -0.01 & 0.02 & -0.01 & 0.01 \\
\hline Partner diagnosis*(Actorªrtner SM) & 0.00 & 0.00 & 0.00 & 0.00 & 0.00 & 0.00 & 0.00 & 0.00 \\
\hline \multicolumn{9}{|c|}{ Moderation of social motivation variables by dyad type } \\
\hline (Actor ${ }^{\star}$ Partner diagnosis) ${ }^{\star}$ Actor SM & 0.01 & 0.01 & -0.00 & 0.02 & 0.00 & 0.01 & $0.03^{\star \star}$ & 0.01 \\
\hline (Actor ${ }^{\star}$ Partner diagnosis) ${ }^{\star}$ Partner SM & -0.00 & 0.01 & 0.02 & 0.01 & 0.02 & 0.01 & -0.00 & 0.01 \\
\hline$\left(\text { Actor }^{\star} \text { Partner diagnosis) }\right)^{\star}$ (Actor ${ }^{\star}$ Partner SM) & -0.00 & 0.00 & 0.00 & 0.00 & 0.00 & 0.00 & 0.00 & 0.00 \\
\hline
\end{tabular}

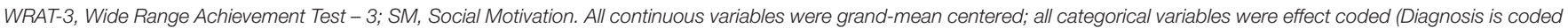

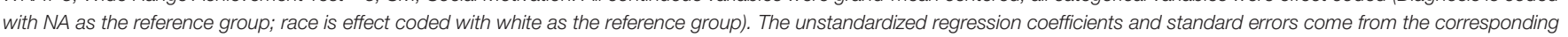
full model in which all of the effects were included. ${ }^{\star} p<0.05,{ }^{* *} p<0.01$.

for autistic adults. Typically, because on average autistic adults perform lower than NA controls on traditional social cognitive tasks (Morrison et al., 2019b), deviate in their social behavior and presentation from prototypical social skills (Morrison et al., 2017), and often report lower or different social motivation (Chevallier et al., 2012a), psychosocial treatments often seek to train autistic people to be more normative in these areas with the hope doing so will translate to greater social interaction success in the real-world (Bishop-Fitzpatrick et al., 2014; Kern Koegel et al., 2016). However, this result does not regularly occur in practice (Gates et al., 2017; Bottema-Beutel et al., 2018). Recent empirical work has shown that social cognitive performance and social skill among autistic adults on standardized measures demonstrate only a small correspondence to their functional outcomes beyond other factors (Sasson et al., 2020), and some autistic people can exhibit normative social skill despite lower theory of mind performance through cognitive compensation (Livingston et al., 2019). Indeed, among autistic adults without intellectual disability, general cognition is far more predictive of social skill than social cognition (Sasson et al., 2020), and performance on explicit social cognitive measures like the ones used here may be less predictive of social communication and interaction behavior in autism than implicit social cognitive performance (Keifer et al., 2020). Taken at face value, results from this study suggest that social cognition, social skill, and social motivation may not be useful treatment targets for improving autistic adults' initial social interactions with NA people. Alternatively, they may still influence real-life social outcomes in autism, but each were either poorly measured in the current study or done so in a way that has limited application to interaction outcomes. From this perspective, the field may improve from the development of more real-world assessments of social cognitive, social motivational, and social skills abilities, rather than continuing to rely solely on paper and pencil and computerized tasks. 
TABLE 13 | Actor-partner interdependence model analyses estimating the combinatorial effects of diagnostic status and social cognition variables on the first impression variables of aggressiveness/dominance, smartness, and liking.

\begin{tabular}{|c|c|c|c|c|c|c|}
\hline \multirow{3}{*}{$\begin{array}{l}\text { Predictors } \\
\text { Social-cognition predictors }\end{array}$} & \multicolumn{6}{|c|}{ First-impression outcome variables } \\
\hline & \multicolumn{2}{|c|}{ Aggressiveness/Dominance } & \multicolumn{2}{|c|}{ Smart } & \multicolumn{2}{|c|}{ Liking } \\
\hline & $b$ & SE & $b$ & SE & $\boldsymbol{b}$ & SE \\
\hline Intercept & 1.74 & 0.10 & 3.46 & 0.14 & 3.35 & 0.09 \\
\hline \multicolumn{7}{|l|}{ Demographic variables } \\
\hline Actor WRAT & -0.00 & 0.01 & -0.01 & 0.01 & 0.00 & 0.01 \\
\hline Actor race - AfricanAmerican & 0.05 & 0.18 & -0.30 & 0.25 & 0.16 & 0.15 \\
\hline Actor race - Asian & 0.08 & 0.20 & 0.25 & 0.27 & $-0.37^{*}$ & 0.17 \\
\hline Actor race - Other & 0.05 & 0.18 & 0.26 & 0.22 & $0.30^{*}$ & 0.15 \\
\hline Actor age & 0.01 & 0.02 & $0.06^{\star \star}$ & 0.02 & 0.02 & 0.01 \\
\hline \multicolumn{7}{|l|}{ Diagnosis variables } \\
\hline Actor diagnosis & 0.16 & 0.09 & -0.14 & 0.09 & -0.06 & 0.07 \\
\hline Partner diagnosis & 0.06 & 0.08 & -0.04 & 0.09 & 0.01 & 0.07 \\
\hline Actor ${ }^{\star}$ Partner diagnosis & -0.00 & 0.07 & $0.21^{\star}$ & 0.10 & 0.01 & 0.06 \\
\hline \multicolumn{7}{|l|}{ Social cognition variables } \\
\hline Actor SC & 0.13 & 0.15 & 0.05 & 0.17 & 0.08 & 0.12 \\
\hline Partner SC & 0.07 & 0.15 & -0.02 & 0.17 & 0.02 & 0.12 \\
\hline Actor ${ }^{\star}$ Partner SC & 0.01 & 0.17 & -0.00 & 0.23 & -0.01 & 0.15 \\
\hline \multicolumn{7}{|c|}{ Moderation of social cognition variables by diagnosis variables } \\
\hline Actor diagnosis ${ }^{\star}$ Actor SC & -0.13 & 0.15 & 0.06 & 0.16 & -0.17 & 0.12 \\
\hline Actor diagnosis*Partner SC & -0.08 & 0.15 & 0.07 & 0.17 & 0.04 & 0.13 \\
\hline Actor diagnosis ${ }^{*}$ (Actor ${ }^{\star}$ Partner SC) & 0.10 & 0.20 & -0.29 & 0.21 & -0.03 & 0.17 \\
\hline Partner diagnosis*Actor SC & -0.01 & 0.16 & 0.26 & 0.18 & 0.18 & 0.13 \\
\hline Partner diagnosis*Partner SC & -0.18 & 0.15 & 0.25 & 0.16 & 0.01 & 0.12 \\
\hline Partner diagnosis`(ActorPartner SC) & -0.02 & 0.20 & 0.20 & 0.21 & 0.33 & 0.17 \\
\hline \multicolumn{7}{|c|}{ Moderation of social cognition variables by dyad type } \\
\hline (Actor $^{\star}$ Partner diagnosis) $)^{\star}$ Actor SC & 0.06 & 0.16 & -0.25 & 0.18 & -0.08 & 0.13 \\
\hline (Actor ${ }^{\star}$ Partner diagnosis) ${ }^{\star}$ Partner SC & 0.10 & 0.15 & -0.01 & 0.17 & 0.12 & 0.13 \\
\hline 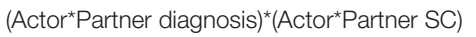 & $-0.44^{\star}$ & 0.17 & 0.14 & 0.23 & -0.18 & 0.14 \\
\hline
\end{tabular}

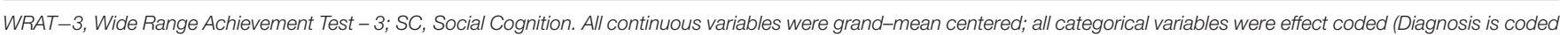

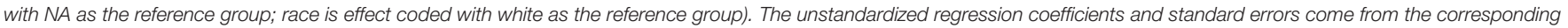
full model in which all of the effects were included. ${ }^{*} p<0.05$, ${ }^{* *} p<0.01$.

The field may also benefit from exploring how other abilities and behaviors of autistic adults may be predictive of how they are evaluated. Some recent work has argued that much remains unknown about social interaction in autism (Bottema-Beutel, 2017; Bottema-Beutel et al., 2018) and has suggested applying new theoretical frameworks for understanding autistic social interaction (Bottema-Beutel, 2017). For example, (BottemaBeutel, 2017) contends that research on social abilities should be examined using sociolinguistic approaches (e.g., conversation analysis) which not only takes the individual's context into account, but also allows for more dynamic assessment of how a person interacts with his or her environment. Additionally, this kind of approach allows for the examination of environmental and societal influences such as stigma that may play a role in how social disability develops and manifests, as well as determining the efficacy of current interventions for treating social disability (Bottema-Beutel et al., 2018). Moreover, given the heterogeneity of autism, a more person-centered approach may better approximate understanding of social difficulties than the group-level assessments and analyses used in this study and most prior work.

This is particularly important because the group-level dyadic analyses pursued here may have been under-powered to detect some effects. The sample size was determined based upon medium to large effects reported in prior interaction studies, but these may have been artificially inflated because of their smaller sample sizes (Usher et al., 2018) or because they examined different populations like the Broad Autism Phenotype (Faso et al., 2016). As a result, the effects here may have been smaller than the medium or large effects that were anticipated, and thus may not have been detectable with the current sample size of 55 dyads. Relatedly, null effects from this study should not be treated as definitive, as some may have reached statistical significance with increased power. Another limitation of the current study is that it used only a few of the social cognitive, social motivational, and social skills assessments that exist, 
TABLE 14 | Actor-partner interdependence model analyses estimating the combinatorial effects of diagnostic status and social skills variables on the first impression variables of aggressiveness/dominance, smartness, and liking.

\begin{tabular}{|c|c|c|c|c|c|c|}
\hline \multirow{3}{*}{$\begin{array}{l}\text { Predictors } \\
\text { Social skills predictors }\end{array}$} & \multicolumn{6}{|c|}{ First-impression outcome variables } \\
\hline & \multicolumn{2}{|c|}{ Aggressiveness/Dominance } & \multicolumn{2}{|c|}{ Smart } & \multicolumn{2}{|c|}{ Liking } \\
\hline & $b$ & SE & $\boldsymbol{b}$ & SE & $\boldsymbol{b}$ & SE \\
\hline Intercept & 1.79 & 0.11 & 3.30 & 0.15 & 3.35 & 0.10 \\
\hline \multicolumn{7}{|l|}{ Demographic variables } \\
\hline Actor WRAT & -0.01 & 0.01 & -0.00 & 0.01 & 0.00 & 0.01 \\
\hline Actor race - AfricanAmerican & 0.00 & 0.18 & -0.22 & 0.24 & 0.13 & 0.17 \\
\hline Actor race - Asian & -0.02 & 0.22 & 0.28 & 0.30 & -0.35 & 0.21 \\
\hline Actor race - Other & 0.04 & 0.17 & 0.28 & 0.21 & 0.28 & 0.16 \\
\hline Actor age & 0.02 & 0.02 & 0.03 & 0.02 & 0.02 & 0.01 \\
\hline \multicolumn{7}{|l|}{ Diagnosis variables } \\
\hline Actor diagnosis & 0.01 & 0.12 & 0.13 & 0.11 & -0.04 & 0.10 \\
\hline Partner diagnosis & 0.07 & 0.12 & -0.13 & 0.11 & -0.01 & 0.09 \\
\hline Actor ${ }^{\star}$ Partner diagnosis & -0.02 & 0.10 & 0.21 & 0.13 & -0.06 & 0.09 \\
\hline \multicolumn{7}{|l|}{ Social skills variables } \\
\hline Actor SS & -0.07 & 0.12 & 0.24 & 0.12 & 0.01 & 0.10 \\
\hline Partner SS & -0.01 & 0.12 & -0.07 & 0.12 & 0.00 & 0.10 \\
\hline Actor ${ }^{\star}$ Partner SS & 0.14 & 0.10 & -0.08 & 0.14 & 0.02 & 0.10 \\
\hline \multicolumn{7}{|c|}{ Moderation of social skills variables by diagnosis variables } \\
\hline Actor diagnosis ${ }^{\star}$ Actor SS & 0.18 & 0.12 & -0.22 & 0.14 & 0.05 & 0.10 \\
\hline Actor diagnosis*Partner SS & -0.04 & 0.12 & 0.12 & 0.14 & 0.08 & 0.10 \\
\hline Actor diagnosis ${ }^{\star}$ (Actor ${ }^{\star}$ Partner SS) & -0.01 & 0.13 & -0.16 & 0.13 & -0.08 & 0.11 \\
\hline Partner diagnosis ${ }^{\star}$ Actor SS & -0.06 & 0.11 & 0.07 & 0.13 & -0.10 & 0.10 \\
\hline Partner diagnosisPartner SS & 0.03 & 0.12 & 0.02 & 0.14 & -0.02 & 0.11 \\
\hline Partner diagnosis*(ActorPartner SS) & -0.01 & 0.13 & 0.21 & 0.13 & 0.06 & 0.11 \\
\hline \multicolumn{7}{|c|}{ Moderation of social skills variables by dyad type } \\
\hline 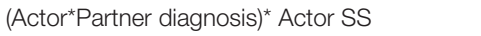 & 0.08 & 0.12 & -0.14 & 0.12 & -0.04 & 0.10 \\
\hline (Actor ${ }^{\star}$ Partner diagnosis) ${ }^{\star}$ Partner SS & -0.00 & 0.12 & 0.10 & 0.12 & 0.02 & 0.10 \\
\hline (ActorPartner diagnosis) $^{\star}$ (ActorPartner SS) & -0.04 & 0.11 & 0.11 & 0.14 & 0.03 & 0.10 \\
\hline
\end{tabular}

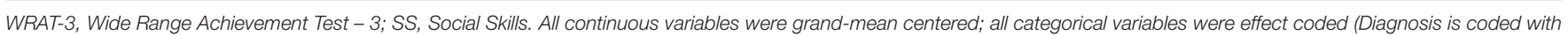

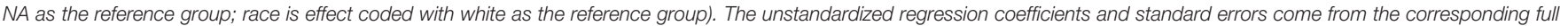
model in which all of the effects were included.

and these may not have been the best measures to capture meaningful relationships within real-world interaction. Further, using social skill and social cognitive composite scores may have obscured more nuanced effects of specific subcomponent abilities. However, exploratory analyses assessing the effect of performance on individual social cognitive tasks also found few links to interaction outcomes. Further, it is possible that other individual mechanisms not assessed here, such as linguistic abilities and executive functioning, may also have been related to outcomes. Moreover, because some of the effects found in this study were relational and not individual, future studies may seek to move beyond examining individual predictors of social interaction outcomes to instead focus on relational variables, like interpersonal synchrony, compatibility, and affiliation.

Effects may also have been smaller than anticipated because of selection biases in the sample: most autistic participants were students attending college or a professional training program and therefore may have been more independent, intellectually capable, and socially skilled than other autistic adults. Nevertheless, they performed comparably to other autistic samples on measures of social cognition (BishopFitzpatrick et al., 2017; Morrison et al., 2019b), normative social skill (Ratto et al., 2011; Morrison et al., 2017), and social motivation (Sedgewick et al., 2016), suggesting they were largely representative in terms of their measured social abilities. Additionally, because NA participants were mostly psychology students attending a university with a sizeable autistic population, they may have more experience with autism than the general population. Finally, because adequately examining the complicating effects of gender on social interaction outcomes would necessitate a prohibitive increase in sample size and additional dyadic conditions, this study was limited to studying interaction between males. Participants were also disproportionately white because of the racial breakdown of our autism recruitment sources. The lack of gender and ethnic diversity in our sample is perhaps the largest limitation of the 


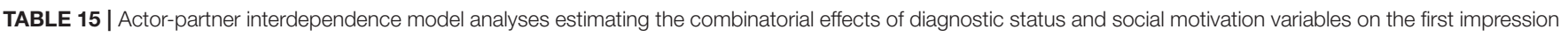
variables of aggressiveness/dominance, smartness, and liking.

\begin{tabular}{|c|c|c|c|c|c|c|}
\hline \multirow{3}{*}{$\begin{array}{l}\text { Predictors } \\
\text { Social motivation predictors }\end{array}$} & \multicolumn{6}{|c|}{ First-impression outcome variables } \\
\hline & \multicolumn{2}{|c|}{ Aggressiveness/Dominance } & \multicolumn{2}{|c|}{ Smart } & \multicolumn{2}{|c|}{ Liking } \\
\hline & $b$ & SE & $b$ & SE & $b$ & SE \\
\hline Intercept & 1.78 & 0.12 & 3.43 & 0.14 & 3.34 & 0.09 \\
\hline \multicolumn{7}{|l|}{ Demographic variables } \\
\hline Actor WRAT & -0.01 & 0.01 & -0.01 & 0.01 & 0.01 & 0.01 \\
\hline Actor race - AfricanAmerican & -0.07 & 0.19 & -0.12 & 0.24 & -0.01 & 0.14 \\
\hline Actor race - Asian & 0.18 & 0.21 & 0.22 & 0.27 & -0.26 & 0.15 \\
\hline Actor race - Other & 0.04 & 0.18 & 0.19 & 0.21 & $0.36^{\star}$ & 0.14 \\
\hline Actor age & 0.01 & 0.02 & $0.04^{\star}$ & 0.02 & 0.02 & 0.01 \\
\hline \multicolumn{7}{|l|}{ Diagnosis variables } \\
\hline Actor diagnosis & 0.00 & 0.08 & 0.03 & 0.08 & -0.02 & 0.07 \\
\hline Partner diagnosis & 0.05 & 0.08 & 0.00 & 0.08 & -0.02 & 0.06 \\
\hline Actor ${ }^{\star}$ Partner diagnosis & 0.08 & 0.07 & 0.09 & 0.09 & -0.00 & 0.05 \\
\hline \multicolumn{7}{|l|}{ Social motivation variables } \\
\hline Actor SM & -0.02 & 0.01 & 0.02 & 0.01 & 0.01 & 0.01 \\
\hline Partner SM & 0.01 & 0.01 & 0.01 & 0.01 & -0.01 & 0.01 \\
\hline ActorPartner SM & -0.00 & 0.00 & -0.00 & 0.00 & $-0.00^{\star}$ & 0.00 \\
\hline \multicolumn{7}{|c|}{ Moderation of social motivation variables by diagnosis variables } \\
\hline Actor diagnosis*Actor SM & -0.00 & 0.01 & 0.01 & 0.01 & -0.02 & 0.01 \\
\hline Actor diagnosisPartner SM & -0.00 & 0.01 & 0.01 & 0.01 & 0.01 & 0.01 \\
\hline Actor diagnosis ${ }^{\star}($ Actor*Partner SM) & 0.00 & 0.00 & -0.00 & 0.00 & 0.00 & 0.00 \\
\hline Partner diagnosisActor SM & -0.00 & 0.01 & -0.01 & 0.01 & 0.01 & 0.01 \\
\hline Partner diagnosis*Partner SM & -0.00 & 0.01 & -0.01 & 0.01 & -0.01 & 0.01 \\
\hline Partner diagnosis* (ActorPartner SM) & -0.00 & 0.00 & 0.00 & 0.00 & 0.00 & 0.00 \\
\hline \multicolumn{7}{|c|}{ Moderation of social motivation variables by dyad type } \\
\hline (ActorPartner diagnosis)*Actor SM & 0.00 & 0.01 & 0.00 & 0.01 & 0.01 & 0.01 \\
\hline (ActorPartner diagnosis)Partner SM & 0.00 & 0.01 & 0.01 & 0.01 & 0.00 & 0.01 \\
\hline (Actor ${ }^{\star}$ Partner diagnosis) $)^{\star}\left(\right.$ Actor $^{\star}$ Partner SM) & 0.00 & 0.00 & -0.00 & 0.00 & 0.00 & 0.00 \\
\hline
\end{tabular}

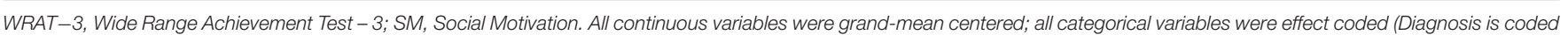

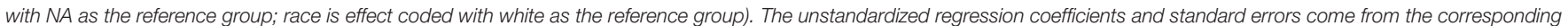
full model in which all of the effects were included. ${ }^{*} p<0.05$.

current study. Gender and race are highly salient characteristics within social interactions, and their effects were not explored here. We hope that future studies can leverage more diverse populations to assess how the findings in this study may differ within all female dyads, as well as within cross-gender and crossracial interactions. In particular, results may be expected to differ for autistic females, who often diverge from autistic males in some aspects of social motivation and behavior (Hull et al., 2017) and tend be evaluated more favorably than autistic males by NA individuals (Cage and Burton, 2019; Cola et al., 2020).

In summary, the current study represents the first comprehensive attempt to directly assess whether and how individual performance on measures of social cognition, social skill, and social motivation among autistic adults predicts their real-world social interaction outcomes with unfamiliar autistic and NA adults. Despite performing lower than NA participants on these measures, autistic adults' performance on each of the three social ability domains was largely unassociated with how autistic adults evaluated-and were evaluated by-their conversation partner. Contrary to prediction, in some cases the social abilities of NA adults were actually more predictive. Taken together, findings from this study raise questions about the predictive utility of standalone measures of social abilities in autistic people for understanding their social interaction difficulties with NA people. Future research should seek to examine and validate measures of real-world social cognition, social skill, and social motivation within an interactive context, and continue to emphasize relational rather than individual predictors of social interaction success.

\section{DATA AVAILABILITY STATEMENT}

The raw data supporting the conclusions of this article will be made available by the authors, without undue reservation. 


\section{ETHICS STATEMENT}

The studies involving human participants were reviewed and approved by The University of Texas at Dallas Institutional Review Board. The patients/participants provided their written informed consent to participate in this study.

\section{AUTHOR CONTRIBUTIONS}

KM led the design of the study, with contributions from RA and NS. KM gathered and organized the data, with contributions from KD and DJ. KM conducted data analysis in collaboration with RA. KM interpreted the data, with help from KD, DJ, RA, and NS. KM and NS wrote the manuscript, with contributions

\section{REFERENCES}

Alkhaldi, R. S., Sheppard, E., and Mitchell, P. (2019). Is there a link between autistic people being perceived unfavorably and having a mind that is difficult to read? J. Autism Dev. Disord. 49, 3973-3982. doi: 10.1007/s10803-019-04101-1

APA (2013). Diagnostic and Statistical Manual of Mental Disorders. 5th Edn. American Psychiatric Publishing.

Aron, A., Melinat, E., Aron, E. N., Vallone, R. D., and Bator, R. J. (1997). The experimental generation of interpersonal closeness: a procedure and some preliminary findings. Pers. Soc. Psychol. Bull. 23, 363-377. doi: $10.1177 / 0146167297234003$

Baranek, G. T. (1999). Autism during infancy: a retrospective video analysis of sensory-motor and social behaviors at 9-12 months of age. J. Autism Dev. Disord. 29, 213-224. doi: 10.1023/A:1023080005650

Baron-Cohen, S. (1991). The theory of mind deficit in autism: how specific is it? Br. J. Dev. Psychol. 9, 301-314. doi: 10.1111/j.2044-835X.1991.tb00879.x

Bauminger, N., and Kasari, C. (2000). Loneliness and friendship in high-functioning children with autism. Child Dev. 71, 447-456. doi: 10.1111/1467-8624.00156

Benton, A. L., Sivan, A. B., de,S, K., Varney, N. R., and Spreen, O. (1983). Facial Recognition: Stimulus and Multiple Choice Pictures: Contributions to Neuropsychological Assessment. New York, NY: Oxford University Press, Incorporated.

Berridge, K. C., Robinson, T. E., and Aldridge, J. W. (2009). Dissecting components of reward: "liking", "wanting", and learning. Curr. Opin. Pharmacol. 9, 65-73. doi: 10.1016/j.coph.2008.12.014

Berry, D. S., and Hansen, J. S. (1996). Positive affect, negative affect, and social interaction. J. Pers. Soc. Psychol. 71, 796-809. doi: 10.1037/0022-3514.71. 4.796

Berscheid, E., Snyder, M., and Omoto, A. M. (1989). The relationship closeness inventory: assessing the closeness of interpersonal relationships. J. Pers. Soc. Psychol. 57, 792-807. doi: 10.1037/0022-3514.57.5.792

Billstedt, E., Gillberg, C., and Gillberg, C. (2005). Autism after adolescence: population-based 13- to 22-year follow-up study of 120 individuals with autism diagnosed in childhood. J. Autism Dev. Disord. 35, 351-360. doi: 10.1007/s10803-005-3302-5

Bishop, D. V. M. (1998). Development of the Children's Communication Checklist (CCC): a method for assessing qualitative aspects of communicative impairment in children. J. Child Psychol. Psychiatry 39, 879-891. doi: 10.1111/1469-7610.00388

Bishop-Fitzpatrick, L., Mazefsky, C. A., Eack, S. M., and Minshew, N. J. (2017). Correlates of social functioning in autism spectrum disorder: the role of social cognition. Res. Autism Spectr. Disord. 35, 25-34. doi: 10.1016/j.rasd.2016. 11.013

Bishop-Fitzpatrick, L., Minshew, N. J., and Eack, S. M. (2014). "A systematic review of psychosocial interventions for adults with autism spectrum disorders," in Adolescents and Adults with Autism Spectrum Disorders, from RA, KD, and DJ. All authors contributed to the article and approved the submitted version.

\section{FUNDING}

This research was supported by a Grant from the Texas Higher Education Coordinating Board's (THECB) Autism Grants Program and by the UT Dallas School of Graduate Studies Small Grant Award for dissertation research.

\section{ACKNOWLEDGMENTS}

We thank the program engagement team at the non-Pareil Institute for their assistance, and Mariel Peterson for supporting the research and professional development of the KM.

eds F. R. Volkmar, B. Reichow, and J. McPartland (Springer). 315-327. doi: 10.1007/978-1-4939-0506-5_16

Bolis, D., Balsters, J., Wenderoth, N., Becchio, C., and Schilbach, L. (2018). Beyond autism: introducing the dialectical misattunement hypothesis and a bayesian account of intersubjectivity. Psychopathology 50, 355-372. doi: $10.1159 / 000484353$

Bottema-Beutel, K. (2017). Glimpses into the blind spot: social interaction and autism. J. Commun. Disord. 68, 24-34. doi: 10.1016/j.jcomdis.2017.06.008

Bottema-Beutel, K., Park, H., and Kim, S. Y. (2018). Commentary on social skills training curricula for individuals with ASD: social interaction, authenticity, and stigma. J. Autism Dev. Disord. 48, 953-964. doi: 10.1007/s10803-017-3400-1

Brothers, L. (1990). The neural basis of primate social communication. Motiv. Emot. 14, 81-91. doi: 10.1007/BF00991637

Cage, E., and Burton, H. (2019). Gender differences in the first impressions of autistic adults. Autism Res. 12, 1495-1504. doi: 10.1002/aur.2191

Cage, E., and Troxell-Whitman, Z. (2019). Understanding the reasons, contexts and costs of camouflaging for autistic adults. J. Autism Dev. Disord. 49, 1899-1911. doi: 10.1007/s10803-018-03878-x

Chevallier, C., Kohls, G., Troiani, V., Brodkin, E. S., and Schultz, R. T. (2012a). The social motivation theory of autism. Trends Cogn. Sci. 16, 231-239. doi: 10.1016/j.tics.2012.02.007

Chevallier, C., Molesworth, C., and Happé, F. (2012b). Diminished social motivation negatively impacts reputation management: autism spectrum disorders as a case in point. PLoS ONE 7:231107. doi: 10.1371/journal.pone.0031107

Cola, M. L., Plate, S., Yankowitz, L., Petrulla, V., Bateman, L., Zampella, C. J., et al. (2020). Sex differences in the first impressions made by girls and boys with autism. Mol. Autism 11, 1-12. doi: 10.1186/s13229-020-00336-3

Constantino, J. N., Przybeck, T., Friesen, D., and Todd, R. D. (2000). Reciprocal social behavior in children with and without pervasive developmental disorders. J. Dev. Behav. Pediatr. 21, 2-11. doi: 10.1097/00004703-200002000-00002

Crompton, C. J., Ropar, D., Evans-Williams, C. V. M., Flynn, E. G., and FletcherWatson, S. (2020). Autistic peer-to-peer information transfer is highly effective. Autism. doi: 10.1177/1362361320919286. [Epub ahead of print].

Dawson, G., Webb, S. J., Wijsman, E., Schellenberg, G., Estes, A., Munson, J., et al. (2005). Neurocognitive and electrophysiological evidence of altered face processing in parents of children with autism: implications for a model of abnormal development of social brain circuitry in autism. Dev. Psychopathol. 17, 679-697. doi: 10.1017/S0954579405050327

Dawson, M., and Cowen, T. (2019). Autistics appear different, but also are different, and this should be valued. Behav. Brain Sci. 42:e85. doi: 10.1017/S0140525X18002467

De Jaegher, H. (2013). Embodiment and sense-making in autism. Front. Integr. Neurosci. 7:15. doi: 10.3389/fnint.2013.00015

Dean, M., Kasari, C., Shih, W., Frankel, F., Whitney, R., Landa, R., et al. (2014). The peer relationships of girls with ASD at school: comparison to boys 
and girls with and without ASD. J. Child Psychol. Psychiatry 55, 1218-1225. doi: $10.1111 /$ jcpp. 12242

DeBrabander, K. M., Morrison, K. E., Jones, D. R., Faso, D. J., Chmielewski, M., and Sasson, N. J. (2019). Do first impressions of autistic adults differ between autistic and nonautistic observers? Autism Adulthood 1, 250-257. doi: 10.1089/aut.2019.0018

Deschrijver, E., Bardi, L., Wiersema, J. R., and Brass, M. (2016). Behavioral measures of implicit theory of mind in adults with high functioning autism. Cogn. Neurosci. 7, 192-202. doi: 10.1080/17588928.2015.1085375

Edey, R., Cook, J., Brewer, R., Johnson, M. H., Bird, G., and Press, C. (2016). Interaction takes two: typical adults exhibit mind-blindness towards those with autism spectrum disorder. J. Abnorm. Psychol. 125, 879-885. doi: 10.1037/abn0000199

Faso, D. J., Corretti, C. A., Ackerman, R. A., and Sasson, N. J. (2016). The broad autism phenotype predicts relationship outcomes in newly formed college roommates. Autism 20, 412-424. doi: 10.1177/1362361315585733

Fletcher-Watson, S., and Crompton, C. J. (2019). Autistic people may lack social motivation, without being any less human. Behav. Brain Sci. 42:e88. doi: 10.1017/S0140525X18002406

Fombonne, E. (2009). Epidemiology of pervasive developmental disorders. Pediatr. Res. 65, 591-580. doi: 10.1203/PDR.0b013e31819e7203

Garman, H. D., Spaulding, C. J., Webb, S. J., Mikami, A. Y., Morris, J. P., and Lerner, M. D. (2016). Wanting it too much: an inverse relation between social motivation and facial emotion recognition in autism spectrum disorder. Child Psychiatry Hum. Dev. 47, 890-902. doi: 10.1007/s10578-015-0620-5

Gates, J. A., Kang, E., and Lerner, M. D. (2017). Efficacy of group social skills interventions for youth with autism spectrum disorder: a systematic review and meta-analysis. Clin. Psychol. Rev. 52, 164-181. doi: 10.1016/j.cpr.2017.01.006

Gernsbacher, M. A., Stevenson, J. L., and Dern, S. (2017). Specificity, contexts, \& reference groups matter when assessing autistic traits. PLOS ONE 12:e0171931. doi: 10.1371/journal.pone.0171931

Golan, O., Baron-Cohen, S., Hill, J. J., and Rutherford, M. D. (2007). The "Reading the mind in the voice" test-revised: a study of complex emotion recognition in adults with and without autism spectrum conditions. J. Autism Dev. Disord. 37, 1096-1106. doi: 10.1007/s10803-006-0252-5

Granieri, J. E., McNair, M. L., Gerber, A. H., Reifler, R. F., and Lerner, M. D. (2020). Atypical social communication is associated with positive initial impressions among peers with autism spectrum disorder. Autism. doi: 10.1177/1362361320924906. [Epub ahead of print].

Grossman, R. B. (2015). Judgments of social awkwardness from brief exposure to children with and without high-functioning autism. Autism 19, 580-587. doi: $10.1177 / 1362361314536937$

Hanley, M., Riby, D. M., McCormack, T., Carty, C., Coyle, L., Crozier, N., et al. (2014). Attention during social interaction in children with autism: comparison to specific language impairment, typical development, and links to social cognition. Res. Autism Spectr. Disord. 8, 908-924. doi: 10.1016/j.rasd.2014.03.020

Happé, F. G. E. (1994). An advanced test of theory of mind: understanding of story characters' thoughts and feelings by able autistic, mentally handicapped, and normal children and adults. J. Autism Dev. Disord. 24, 129-154. doi: 10.1007/BF02172093

Heasman, B., and Gillespie, A. (2019). Neurodivergent intersubjectivity: distinctive features of how autistic people create shared understanding. Autism 23, 910-921. doi: 10.1177/1362361318785172

Heerey, E. A. (2015). Decoding the dyad: challenges in the study of individual differences in social behavior. Curr. Dir. Psychol. Sci. 24, 285-291. doi: $10.1177 / 0963721415570731$

Heerey, E. A., and Kring, A. M. (2007). Interpersonal consequences of social anxiety. J. Abnorm. Psychol. 116, 125-134. doi: 10.1037/0021-843X.116.1.125

Hehman, E., Sutherland, C. A. M., Flake, J. K., and Slepian, M. L. (2017). The unique contributions of perceiver and target characteristics in person perception. J. Pers. Soc. Psychol. 113, 513-529. doi: 10.1037/pspa00 00090

Hintzen, A., Delespaul, P., van Os, J., and Myin-Germeys, I. (2010). Social needs in daily life in adults with Pervasive Developmental Disorders. Psychiatry Res. 179, 75-80. doi: 10.1016/j.psychres.2010.06.014

Hull, L., Mandy, W., and Petrides, K. V. (2017). Behavioural and cognitive sex/gender differences in autism spectrum condition and typically developing males and females. Autism 21, 706-727. doi: 10.1177/136236131666 9087

Hus, V., and Lord, C. (2014). The autism diagnostic observation schedule, module 4: revised algorithm and standardized severity scores. J. Autism Dev. Disord. 44, 1996-2012. doi: 10.1007/s10803-014-2080-3

Joseph, R. M., and Tanaka, J. (2003). Holistic and part-based face recognition in children with autism. J. Child Psychol. Psychiatry 44, 529-542. doi: 10.1111/1469-7610.00142

Keifer, C. M., Mikami, A. Y., Morris, J. P., Libsack, E. J., and Lerner, M. D. (2020). Prediction of social behavior in autism spectrum disorders: explicit versus implicit social cognition. Autism. 24, 1758-1772. doi: $10.1177 / 1362361320922058$

Kennedy, D. P., and Adolphs, R. (2012). Perception of emotions from facial expressions in high-functioning adults with autism. Neuropsychologia 50, 3313-3319. doi: 10.1016/j.neuropsychologia.2012.09.038

Kenny, D. A., Duck, S., Hay, D. F., Hobfoll, S. E., Ickes, W., and Montgomery, B. M. (1988). "The analysis of data from two-person relationships," in Handbook of Personal Relationships: Theory, Research and Interventions, eds S. Duck, D. F. Hay, S. E. Hobfoll, W. Ickes, and B. M. Montgomery (Oxford: John Wiley \& Sons) $57-77$.

Kenny, D. A., Kashy, D. A., and Cook, W. L. (2006). Dyadic Data Analysis. Methodology in the Social Sciences. New York, NY: Guilford.

Kern Koegel, L., Ashbaugh, K., Navab, A., and Koegel, R. L. (2016). Improving empathic communication skills in adults with autism spectrum disorder. J. Autism Dev. Disord. 46, 921-933. doi: 10.1007/s10803-015-2633-0

Klin, A., Jones, W., Schultz, R., Volkmar, F., and Cohen, D. (2002). Visual fixation patterns during viewing of naturalistic social situations as predictors of social competence in individuals with autism. Arch. Gen. Psychiatry 59, 809-816. doi: 10.1001/archpsyc.59.9.809

Klin, A., Sparrow, S. S., De Bildt, A., Cicchetti, D. V., Cohen, D. J., and Volkmar, F. R. (1999). A normed study of face recognition in autism and related disorders. J. Autism Dev. Disord, 29, 499-508. doi: 10.1023/A:1022299920240

Kohler, C. G., Bilker, W., Hagendoorn, M., Gur, R. E., and Gur, R. C. (2000). Emotion recognition deficit in schizophrenia: association with symptomatology and cognition. Biol. Psychiatry 48, 127-136. doi: 10.1016/S0006-3223(00)00847-7

Kraemer, H. C., and Jacklin, C. N. (1979). Statistical analysis of dyadic social behavior. Psychol. Bull. 86, 217-224. doi: 10.1037/0033-2909.86.2.217

Lasgaard, M., Nielsen, A., Eriksen, M. E., and Goossens, L. (2010). Loneliness and social support in adolescent boys with autism spectrum disorders. J. Autism Dev. Disord. 40, 218-226. doi: 10.1007/s10803-009-0851-z

Lerner, M. D., and Mikami, A. Y. (2012). A preliminary randomized controlled trial of two social skills interventions for youth with high-functioning autism spectrum disorders. Focus Autism Other Dev. Disabl. 27, 147-157. doi: $10.1177 / 1088357612450613$

Livingston, L. A., Colvert, E., Bolton, P., and Happé, F. (2019). Good social skills despite poor theory of mind: exploring compensation in autism spectrum disorder. J. Child Psychol. Psychiatry 60, 102-110. doi: 10.1111/jcpp.12886

Lord, C., Risi, S., Lambrecht, L., Cook, E. H., Leventhal, B. L., Dilavore, P. C., et al. (2000). The autism diagnostic observation schedule-generic: a standard measure of social and communication deficits associated with the spectrum of autism. J. Autism Dev. Disord. 30, 206-223. doi: 10.1023/A:1005592401947

Markey, P., Lowmaster, S., and Eichler, W. (2010). A real-time assessment of interpersonal complementarity. Pers. Relatsh. 17, 13-25. doi: 10.1111/j.1475-6811.2010.01249.x

Markey, P. M., and Markey, C. N. (2007). Romantic ideals, romantic obtainment, and relationship experiences: the complementarity of interpersonal traits among romantic partners. J. Soc. Pers. Relat. 24, 517-533. doi: 10.1177/0265407507079241

Mathersul, D., McDonald, S., and Rushby, J. A. (2013). Understanding advanced theory of mind and empathy in high-functioning adults with autism spectrum disorder. J. Clin. Exp. Neuropsychol. 35, 655-668. doi: $10.1080 / 13803395.2013 .809700$

Mazurek, M. O. (2014). Loneliness, friendship, and well-being in adults with autism spectrum disorders. Autism 18, 223-232. doi: 10.1177/1362361312474121

McClelland, G. H., Irwin, J. R., Disatnik, D., and Sivan, L. (2017). Multicollinearity is a red herring in the search for moderator variables: a guide to 
interpreting moderated multiple regression models and a critique of iacobucci, schneider, popovich, and Bakamitsos (2016). Behav. Res. Methods 49, 394-402. doi: 10.3758/s13428-016-0785-2

McDonald, S., Flanagan, S., Rollins, J., and Kinch, J. (2003). TASIT: a new clinical tool for assessing social perception after traumatic brain injury. J. Head Trauma Rehabil. 18, 219-238. doi: 10.1097/00001199-200305000-0 0001

Milton, D. E. M. (2012). On the ontological status of autism: the "double empathy problem.” Disabil. Soc. 27, 883-887. doi: 10.1080/09687599.2012.7 10008

Milton, D. E. M. (2017). A Mismatch of Salience: Explorations of the Nature of Autism from Theory to Practice. Hove: Pavilion Press.

Moriuchi, J. M., Klin, A., and Jones, W. (2017). Mechanisms of diminished attention to eyes in Autism. Am. J. Psychiatry 174, 26-35. doi: 10.1176/appi.ajp.2016.150 91222

Morrison, K. E., DeBrabander, K. M., Faso, D. J., and Sasson, N. J. (2019a). Variability in first impressions of autistic adults made by neurotypical raters is driven more by characteristics of the rater than by characteristics of autistic adults. Autism 23, 1817-1829. doi: 10.1177/13623613188 24104

Morrison, K. E., DeBrabander, K. M., Jones, D. R., Faso, D. J., Ackerman, R. A., and Sasson, N. J. (2020). Outcomes of real-world social interaction for autistic adults paired with autistic compared to typically developing partners. Autism 24, 1067-1080. doi: 10.1177/1362361319892701

Morrison, K. E., Pinkham, A. E., Kelsven, S., Ludwig, K., Penn, D. L., and Sasson, N. J. (2019b). Psychometric evaluation of social cognitive measures for adults with autism. Autism Res. 12, 766-778. doi: 10.1002/aur.2084

Morrison, K. E., Pinkham, A. E., Penn, D. L., Kelsven, S., Ludwig, K., and Sasson, N. J. (2017). Distinct profiles of social skill in adults with autism spectrum disorder and schizophrenia. Autism Res. 10, 878-887. doi: 10.1002/aur.1734

Mueser, K. T., and Bellack, A. S. (1998). "Social skills and social functioning," in Handbook of Social Functioning in Schizophrenia, eds K. T. Mueser and N. Tarrier (Boston, MA: Allyn \& Bacon), 79-96.

Nangle, D. W., Grover, R. L., Holleb, L. J., Cassano, M., and Fales, J. (2010). "Defining competence and identifying target skills," in Practioner's Guide to Empirically Based Measures of Social Skills eds Nangle, D. W., Hansen, D. J., Erdley, C. A., and Norton, P. J. (New York, NY: Springer), 3-19. doi: 10.1007/978-1-4419-0609-0_1

Neves, M., de das, C. L., Tremeau, F., Nicolato, R., Lauar, H., Romano-Silva, M. A., et al. (2011). Facial emotion recognition deficits in relatives of children with autism are not associated with 5HTTLPR. Braz. J. Psychiatry 22, 261-267. doi: 10.1590/S1516-44462011005000018

Pallathra, A. A., Cordero, L., Wong, K., and Brodkin, E. S. (2019). Psychosocial interventions targeting social functioning in adults on the autism spectrum: a literature review. Curr. Psychiatry Rep. 21:5. doi: 10.1007/s11920-019-0989-0

Palmen, A., Didden, R., and Korzilius, H. (2010). Effectiveness of behavioral skills training on staff performance in a job training setting for high-functioning adolescents with autism spectrum disorders. Res. Autism Spectr. Disord. 4, 731-740. doi: 10.1016/j.rasd.2010. 01.012

Patterson, T. L., Moscona, S., McKibbin, C. L., Davidson, K., and Jeste, D. V. (2001). Social skills performance assessment among older patients with schizophrenia. Schizophr. Res. 48, 351-360. doi: 10.1016/S0920-9964(00) $-2$

Pelphrey, K., Adolphs, R., and Morris, J. P. (2004). Neuroanatomical substrates of social cognition dysfunction in autism. Ment. Retard. Dev. Disabil. Res. Rev. 10, 259-271. doi: 10.1002/mrdd.20040

Philip, R. C. M., Whalley, H. C., Stanfield, A. C., Sprengelmeyer, R., Santos, I. M., Young, A. W., et al. (2010). Deficits in facial, body movement and vocal emotional processing in autism spectrum disorders. Psychol. Med. 40, 1919-1929. doi: 10.1017/S00332917099 92364

Pierce, K., Conant, D., Hazin, R., Stoner, R., and Desmond, J. (2011). Preference for geometric patterns early in life as a risk factor for autism. Arch. Gen. Psychiatry 68, 101-109. doi: 10.1001/archgenpsychiatry.2010.113

Pinkham, A. E., and Penn, D. L. (2006). Neurocognitive and social cognitive predictors of interpersonal skill in schizophrenia.
Psychiatry Res 143, 167-178. doi: 10.1016/j.psychres.2005. 09.005

Powell, S., Plamondon, R., and Retzlaff, P. (2002). Screening cognitive abilities in adults with developmental disabilities: correlations of the K-BIT, PPVT-3, WRAT-3, and CVLT. J. Dev. Phys. Disabil. 14, 239-246. doi: 10.1023/A:10160846 04822

Ratto, A. B., Turner-Brown, L., Rupp, B. M., Mesibov, G. B., and Penn, D. L. (2011). Development of the Contextual Assessment of Social Skills (CASS): a role play measure of social skill for individuals with high-functioning autism. J. Autism Dev. Disord. 41, 1277-1286. doi: 10.1007/s10803-010-1 $147-\mathrm{z}$

Redcay, E., and Schilbach, L. (2019). Using second-person neuroscience to elucidate the mechanisms of social interaction. Nat. Rev. Neurosci. 20, 495-505. doi: 10.1038/s41583-019-0179-4

Richard, J. F., and Schneider, B. H. (2005). Assessing friendship motivation during preadolescence and early adolescence. J. Early Adolesc. 25, 367-385. doi: 10.1177/0272431605 276930

Sasson, N. J., Faso, D. J., Nugent, J., Lovell, S., Kennedy, D. P., and Grossman, R. B. (2017). Neurotypical peers are less willing to interact with those with autism based on thin slice judgments. Sci. Rep. 7:40700. doi: 10.1038/srep40700

Sasson, N. J., and Morrison, K. E. (2019). First impressions of adults with autism improve with diagnostic disclosure and increased autism knowledge of peers. Autism 23, 50-59. doi: 10.1177/13623613177 29526

Sasson, N. J., Morrison, K. E., Kelsven, S., and Pinkham, A. E. (2020). Social cognition as a predictor of functional and social skills in autistic adults without intellectual disability. Autism Res. 13, 259-270. doi: 10.1002/aur.2195

Sasson, N. J., Nowlin, R. B., and Pinkham, A. E. (2013). Social cognition, social skill, and the broad autism phenotype. Autism 17, 655-667. doi: $10.1177 / 1362361312455704$

Sasson, N. J., Pinkham, A. E., Carpenter, K. L. H., and Belger, A. (2011). The benefit of directly comparing autism and schizophrenia for revealing mechanisms of social cognitive impairment. J. Neurodev. Disord. 3, 87-100. doi: 10.1007/s11689-010-9068-x

Sasson, N. J., Pinkham, A. E., Weittenhiller, L. P., Faso, D. J., and Simpson, C. (2016). Context effects on facial affect recognition in schizophrenia and autism: behavioral and eye-tracking evidence. Schizophr. Bull. 42, 675-683. doi: $10.1093 /$ schbul/sbv176

Sedgewick, F., Hill, V., Yates, R., Pickering, L., and Pellicano, E. (2016) Gender differences in the social motivation and friendship experiences of autistic and non-autistic adolescents. J. Autism Dev. Disord. 46, 1297-1306. doi: 10.1007/s10803-015-2669-1

Sheppard, E., Pillai, D., Wong, G. T. L., Ropar, D., and Mitchell, P. (2016). How easy is it to read the minds of people with autism spectrum disorder? J. Autism Dev. Disord. 46, 1247-1254. doi: 10.1007/s10803-015-2 662-8

Spek, A. A., Scholte, E. M., and Van Berckelaer-Onnes, I. A. (2010). Theory of mind in adults with HFA and asperger syndrome. J. Autism Dev. Disord. 40, 280-289. doi: 10.1007/s10803-009-0860-y

Stevanovic, M., Henttonen, P., Koski, S., Kahri, M., Voutilainen, L., Koskinen, E., et al. (2017). On the asperger experience of interaction: interpersonal dynamics in dyadic conversations. J. Autism 4:2. doi: 10.7243/2054-992X-4-2

Taylor, J. L., Henninger, N. A., and Mailick, M. R. (2015). Longitudinal patterns of employment and postsecondary education for adults with autism and average-range IQ. Autism 19, 785-793. doi: 10.1177/1362361315 585643

Uljarevic, M., and Hamilton, A. (2013). Recognition of emotions in autism: a formal meta-analysis. J. Autism Dev. Disord. 43, 1517-1526. doi: 10.1007/s10803-012-1695-5

Usher, L. V., Burrows, C. A., Messinger, D. S., and Henderson, H. A. (2018). Metaperception in adolescents with and without autism spectrum disorder. $J$. Autism Dev. Disord. 48, 533-548. doi: 10.1007/s10803-017-3356-1

Verhoeven, E. W. M., Smeekens, I., and Didden, R. (2013). Brief report: suitability of the social skills performance assessment (SSPA) for the assessment of social skills in adults with Autism spectrum disorders. J. Autism Dev. Disord. 43, 2990-2996. doi: 10.1007/s10803-013-1843-6 
Wechsler, D. (2011). Wechsler Abbreviated Scale of Intelligence-Second Edition (WASI-II) San Antonio, TX: NCS Pearson. doi: 10.1037/t15171-000

Whitehouse, A. J. O., Durkin, K., Jaquet, E., and Ziatas, K. (2009). Friendship, loneliness and depression in adolescents with asperger's syndrome. J. Adolesc. 32, 309-322. doi: 10.1016/j.adolescence.2008.03.004

Wilkinson, G. (1993). Wide Range Achievement Test. Wilmington, DE: Wide Range Inc.

Wykes, T., Steel, C., Everitt, B., and Tarrier, N. (2008). Cognitive behavior therapy for schizophrenia: effect sizes, clinical models, and methodological rigor. Schizophr. Bull. 34, 523-537. doi: 10.1093/schbul/ sbm114
Conflict of Interest: The authors declare that the research was conducted in the absence of any commercial or financial relationships that could be construed as a potential conflict of interest.

Copyright (c) 2020 Morrison, DeBrabander, Jones, Ackerman and Sasson. This is an open-access article distributed under the terms of the Creative Commons Attribution License (CC BY). The use, distribution or reproduction in other forums is permitted, provided the original author(s) and the copyright owner(s) are credited and that the original publication in this journal is cited, in accordance with accepted academic practice. No use, distribution or reproduction is permitted which does not comply with these terms. 